\title{
El Yapımı Patlayıcıların ve Patlayıcı Maddelerin Tespitinde Kullanılan Spektroskopi Tabanlı Yöntemlerin Karşılaştırılmasına İlişkin Bir İnceleme
}

\author{
Seniha Esen YÜKSEL ${ }^{*}$, Sefa KÜÇÜK ${ }^{* *}$, Vedat TEKELİ ${ }^{* * *}$, \\ Birol KILIÇ ${ }^{* * * *}$, R. Hamza KARAKAYA ${ }^{* * * * *}$, Murat Berkay ZEKA ${ }^{* * * * * * *}$ \\ $\ddot{O} z$
}

El Yapımı Patlayıcılar (EYP) ve patlayıcı maddeler nedeniyle her yıl binlerce kişi ölmekte, yaralanmakta ve psikolojik olarak zarar görmektedir. Ülkeler ulusal güvenliklerini sağlamak maksadiyla muazzam çaba sarf etmekte ve EYP'lere karşı tedbirler geliştirebilmek için hatırı sayılır harcamalar yapmaktadırlar. En güçlü orduların bile tespiti için çözüm geliştirmekte zorlandı̆̆ EYP'ler, Türk Silahlı Kuvvetleri için de büyük bir problem oluşturmaktadır. Son yıllarda ülkemizdeki terör eylemlerinde de sıklıkla kullanılması nedeniyle EYP ile mücadele her geçen gün daha çok önem kazanmaktadır.

\footnotetext{
* Doç. Dr., Hacettepe Üniversitesi, Elektrik ve Elektronik Mühendisliği Bölümü, 06800, Beytepe, Ankara, Türkiye. eyuksel@ee.hacettepe.edu.tr; ORCID: 0000-0002-8868-1132

** Arş. Gör., Hacettepe Üniversitesi, Elektrik ve Elektronik Mühendisliği Bölümü, 06800, Beytepe, Ankara, Türkiye.skucuk@ee.hacettepe.edu.tr; ORCID: 0000-0002-0279-3185

*** Elektrik Elektronik Mühendisi, Millî Savunma Üniversitesi Alparslan Savunma Bilimleri Enstitüsü KBRN-P ABD EYP ve Patlayıcı Maddeler ile Mücadele Programı Yüksek Lisans Öğrencisi, vedat.tekeli@msb.gov.tr; ORCID: 0000-0003-0386-8713

**** İs.Yzb., Millî Savunma Üniversitesi Alparslan Savunma Bilimleri Enstitüsü KBRN-P ABD EYP ve Patlayıcı Maddeler ile Mücadele Programı Yüksek Lisans Öğrencisi, klcbrl@gmail.com; ORCID: 0000-0002-0515-7125

***** Bkm.Yzb., Millî Savunma Üniversitesi Alparslan Savunma Bilimleri Enstitüsü KBRN-P ABD EYP ve Patlayıcı Maddeler ile Mücadele Programı Yüksek Lisans Öğrencisi, rhkarakaya@gmail.com; ORCID: 0000-0002-7863-1756

******* Makine Mühendisi, Millî Savunma Üniversitesi Alparslan Savunma Bilimleri Enstitüsü KBRN-P AD EYP ve Patlayıcı Maddeler ile Mücadele Programı Yüksek Lisans Öğrencisi, zekaberkay@gmail.com; ORCID: 0000-0002-8515-8629
}

Geliş Tarihi/Received : 13.02.2020

Kabul Tarihi/Accepted : 14.10.2020

Araştırma Makalesi/Research Article DOI: 10.17134/khosbd.913675 
Satıh altına gömülmüş bir patlayıcı maddenin tespit edilmesi; arazi yapısı, çevre koşulları, iklim yapısı ve gömülü maddenin özellikleri hakkında bilgi edinilmesini gerektiren zorlu bir süreçtir. Tespit yönteminin kullanılacă̆ arazi şartları, ihtiyaç duyulan uzaklık, hassasiyet ve süre gibi pek çok değişken sebebiyle standart bir EYP tespit yöntemi bulunmamaktadır. Bu nedenle dünyada çok çeşitli yöntemler üzerine birçok çalışma yürümektedir. Fakat patlayıcı maddeleri tespit ederken kullanılan her teknik ve usul faydal olamamakta ve doğru sonuç vermemektedir. Tespit edilmesi arzulanan patlayıcı maddenin cinsine, çevresel etkenlerine, mesafesine, zemin altındaki derinliğine, kimyasal bileşenlerine vb. faktörlere göre en uygun tekniğin seçilmesi icap etmektedir.

Bu makalede, önce patlayıcı ve EYP'ler hakkında genel bilgi verilmiş, kimyasal yapıları ve tespit teknolojileri incelenmiştir. Daha sonra da EYP tespitinde kullanılan spektroskopi tabanl dört yöntem ele alınmış, hangi durumlarda kullanılabilir olacaklart, avantajları ve dezavantajları incelenmiştir. Otomatik ve temassiz olarak kullanabilecek ve elektromanyetik spektrumun (EM) farkl alanlarına yoğunlaşarak patlayıcı tespitine farklı pencerelerden bakan bu yöntemler şunlardır: (i) Hiperspektral Görüntüleme, (ii) Fourier Dönüşüm Kızılötesi (FT-IR) Spektroskopisi, (iii) Terahertz Teknolojisi, (iv) Lazer Etkileşimli Plazma Spektroskopisi (LIBS). Bu yöntemler, yığın veya iz patlayıcı bulmadaki başarıları, laboratuvar ortamında veya operasyonel olarak kullanımlarl ve insan sağlı̆̆ına etkileri açısından değerlendirilmişlerdir. Son olarak da patlayıcı ve EYP'lerin otomatik tespitinde dikkat edilmesi gereken hususlar verilmiş ve bu alandaki gelişmelerin geleceği tartışılmıştır.

Anahtar Kelimeler: El Yapımı Patlayıcı (EYP), Fourier Dönüşüm Kızılötesi (FT-IR) Spektroskopisi, Hiperspektral Görüntüleme, Lazer Etkileşimli Plazma Spektroskopisi (LIBS), Terahertz Teknolojisi.

\title{
A Study on the Comparison of Spectroscopy-based Methods Used in the Detection of Improvised Explosive Devices and Explosives
}

\author{
Abstract \\ Thousands of people are killed, injured and psychologically damaged every year by \\ Improvised Explosive Devices (IED) and explosives. For this reason, countries have
}


El Yapımı Patlayıcıların ve Patlayıcı Maddelerin Tespitinde Kullanılan Spektroskopi Tabanlı Yöntemlerin Karşılaştırılmasına İlişkin Bir İnceleme

made tremendous efforts and spent a considerable amount of their budget to ensure their national security. IEDs, which even the most powerful armies find it difficult to develop solutions to take countermeasures, are a major problem for the Turkish Armed Forces. In recent years, the fight against IEDs has become more and more important as it is frequently used in terrorist acts in Turkey.

Detection of an explosive buried beneath the surface is a challenging process that requires obtaining information about the terrain, environmental conditions, climatic structure and characteristics of the buried material. There is no standard detection method due to many variables such as the conditions under which the detection method will be used, the required distance, sensitivity and speed. For this reason, there are many ongoing studies around the world. However, not all techniques and methods used to detect explosives are useful and do not provide accurate results. Depending on the type of explosive substance to be detected, environmental factors, distance, depth under the ground, chemical components and such factors should be considered for selecting the most appropriate technique. In this article, firstly general information about explosives and IEDs are given and their chemical structures and detection technologies are examined. Then, four spectroscopy-based methods used in IED detection are discussed; their advantages and disadvantages are examined. These automatic and non-contact methods focus on different areas of the electromagnetic spectrum (EM) and deal with explosive detection in different ways. These techniques are: (i) Hyperspectral Imaging, (ii) Fourier Transform Infrared (FT-IR) Spectroscopy, (iii) Terahertz Technology (iv) Laser Induced Breakdown Spectroscopy (LIBS). These methods have been evaluated in terms of their success in finding bulk or trace explosives, their use in laboratory or operational conditions and their effects on human health. Finally, the issues to be considered in automatic detection of explosives and IEDs, and the future of the developments in this field are discussed.

Keywords: Improvised Explosive Device (IED), Fourier Transformation Infrared (FT-IR) Spectroscopy, Hyperspectral Imaging, Laser Induced Breakdown Spectroscopy (LIBS), Terahertz Technology. 
Seniha Esen YÜKSEL, Sefa KÜÇÜK, Vedat TEKELİ, Birol KILIÇ, R.Hamza KARAKAYA, Murat Berkay ZEKA

\section{Giriş}

Günümüzdeki çatışmaların iki ülkenin ordusu arasında yaşanmaktan çıkıp, devlet dışı aktörler ile ordular arasında asimetrik bir savaş halini aldığı görülmektedir. Devlet dışı aktörler bu savaşlarda askerleri ya da sivilleri öldürmek, araç veya malzemeleri tahrip etmek, zarar vermek, toplumda korku ve panik yaratmak gibi amaçlar için sıklıkla EYP kullanmaktadırlar. Bu EYP'ler atılmış, patlamamış mühimmatın tuzaklanması ile yapılabildiği gibi, diğer amaçlarla imal edilmiş malzemelerin bir araya getirilerek kullanılması ile de elde edilebilmektedir. Terör unsurları, bilinen hazır patlayıcı maddelerin yanı sıra sanayi, temizlik, ilaç ve kozmetik gibi sektörlerden tedarik edilebilen ticari kimyasalları da kullanarak farklı tip patlayıcılar sentezlemekte ve EYP'ler üretebilmektedir. Londra ulaşım ağında gerçekleşen patlamada kullanılan Triacetone Triperoxide (TATP), terörist unsurlarca sentezlenen EYP'lere iyi bir örnek olarak verilebilir (Hildenbrand vd., 2009).

EYP'ler etkilerinin yüksek, maliyetlerinin düşük olması, kolay elde edilebilir ve kullanılabilir olmaları nedenleri ile terör unsurları tarafindan sıklıkla tercih edilmekte ve kullanılmaktadır. Merkez Strateji Enstitüsü El Yapımı Patlayıcılar Seminerinde sadece 2011 yılı içinde tüm dünyada ABD ordusunun 16.500 EYP olayı ile yüz yüze geldiği ifade edilmektedir (Bingöl ve Varlık, 2015). Birleşmiş Milletler verilerine göre 2017 y1lında Orta Doğu'daki şehir savaşlarında patlayıcı mühimmatlar sebebiyle hayatını kaybeden dört insandan üçünün savunmasız siviller olduğu belirtilmektedir (www.unocha.org, 2018). Mayın ve EYP'ler, ülkemizde de terör unsurları tarafindan aktif olarak kullanılmakta, çok sayıda askeri ve sivil kayıplara neden olmaktadır. 2011-2018 y1lları arasında 5.031

ölüm veya yaralanmanın patlayıcılardan olduğu bildirilmektedir (https://aoav.org.uk/ explosive violence/turkey/, 2018).

Ne yazık ki sadece teröristlerin elindeki malzemeler ve karanlık hayal güçleriyle sınırlı olan EYP'ler, çok çeşitli tip ve içerikte olduklarından, çok farklı düzeneklerle tetiklenebildiklerinden ve bilinen bir formlarının olmayışı dolayısıyla çok zor tespit edilebilmektedirler. En güçlü orduların dahi çözüm geliştirmekte zorlandığı bu konu, Türk Silahlı Kuvvetleri için de büyük bir problem oluşturmaktadır. Dolayısıyla birçok grup, hem hızlı ve doğruluğu yüksek ölçümler verecek hem de insan hatasını azaltacak, bu sayede de sivil ve askerî kayıları 
El Yapımı Patlayıcıların ve Patlayıcı Maddelerin Tespitinde Kullanılan

Spektroskopi Tabanlı Yöntemlerin Karşılaştırılmasına İlişskin Bir İnceleme

engelleyecek sistemler geliştirmeye çalışmaktadır. Hatta daha geniş bir pencereden bakılarak, konu sadece EYP tespiti olarak değil, patlayıcı maddeler, patlayıcı mühimmat, patlamamış mühimmat, terk edilmiş mühimmat ve mayınların tespiti olarak da çalışılmaktadır.

İdeal bir sistemden, birçok patlayıcı türünü tespit edip etiketleyebilmesi, patlayıcının kendisini olduğu kadar emarelerini de tespit edebilmesi, farklı hedeflere uyum sağlayabilmesi, hem gömülü hem yüzeydeki hedefleri tespit etmesi, tehdide bağlı olarak farklı türde (örneğin elde tutulabilen veya uzaktan) kullanılabilmesi, geniş bir alanı tarayabilmesi, patlayıcının içinde bulunduğu hava ve toprak koşullarından bağımsız olarak yüksek pozitif algılama olasılığı ve düşük yanlış alarm olasılığına sahip olması istenmektedir. Ayrıca, ideal bir sistemden karşı önlemlere veya müdahalelere olan açıklarının sınırlı, kullanımının kolay, bakım gereksinimlerinin az, maliyet, alan ve güç gereksinimlerinin düşük, güvenilirliğinin yüksek olması beklenmektedir (Pellegrino vd., 2015). Ancak günümüzde böyle ideal bir sistem bulunmamaktadır. Hatta, gelecekte de böyle bir sistem olursa, tek bir sistem içermeyeceği, farklı sistemlerin birleşmesinden meydana geleceği ve hepsinin ayrı ayrı zaaflarına maruz kalacağı öngörülmektedir. Dolayısıyla, günümüzde, hem ayrı ayrı sensörlerin geliştirilmesine, hem de bu sensörlerin birleştirilmesine çalışılmaktadır (Moros vd., 2010; Zhang vd., 2018).

$\mathrm{Bu}$ makalenin ilerleyen kısımlarında, öncelikle genel olarak EYP ve patlayıcı tespitine değinilmiştir. Sonrasında, patlayıcı madde tespitinde en gelişmiş teknolojilerden olan, önümüzdeki yıllarda patlayıcı tespitinde önemli rol oynayacağı öngörülen ve şu anda farklı cihazlar olarak değerlendirilen, fakat belki ileride lazerleri, spektrometreleri ya da optik yolları birleştirilebilecek dört spektroskopik yöntem avantajları ve dezavantajları ile detaylı olarak verilmiştir.

\section{Patlayıcı Madde Tespit Teknolojilerine Genel Bir Bakış}

Patlayıcı maddelerin ve kimyasalların tespitinde yığın patlayıcı tespiti ve eser patlayıcı tespiti olmak üzere iki temel yaklaşım bulunmaktadır. Yığın patlayıcı tespit yöntemleri ile büyük miktarlı patlayıcının tespiti hedeflenirken, eser patlayıcı tespit yöntemleri ile iz/kalıntı tespiti amaçlanmaktadır. Şekil 1'de gösterilen bu tespit yöntemlerinde, elektromanyetik tayfın nerdeyse tüm bölgeleri (radyo dalgası, mikrodalga, kızılötesi, görünür, morötesi, X ışını, gama 1şını gibi) patlayıcı tespiti maksadıyla araştırılmıştır (National Research Council, 2004). Dolayısıyla bu 
yöntemlerin avantaj ve dezavantajlarını bilmek, ona göre operasyonel anlamda bilinçli bir seçim yapmak veya bu yöntemlerin avantajlarını bir araya getirecek yeni sistemleri seçmek gerekmektedir.
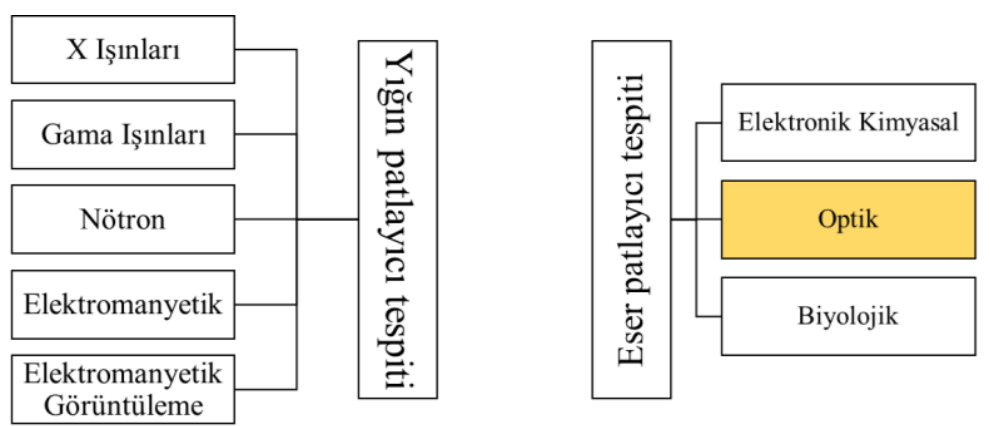

Şekil 1. Tespit Yöntemleri

Şekil 1'de görüldüğü üzere, eser patlayıcı tespitinde, öteden beri kullanıla gelen köpekler gibi koku duyusu gelişmiş diğer canlılara ilişkin çalışmalar sürdürülmektedir. Arılar, fareler ve bakteriler mayın ve patlayıcı tespitinde başarı göstermiş canlılardır (Cross, 2017; Habib, 2007; Guest 2020). Ayrıca bazı antikorların da patlayıcılara bağlanabildiği bilinmektedir (Shankaran vd., 2005). Bunların yanısıra, optik alandaki çeşitli çalışmalar patlayıcıların araba kollarında, kıyafetlerde ve insan saçında da tespit edilebildiğini göstermektedir (Chirico vd. 2012; Cullum vd. 2004; Oxley vd. 2007; Oxley vd. 2012; Yüksel vd. 2012; Yüksel vd. 2013). Ayrıca, yakın bölgeden veya laboratuvar ortamında başarılı şekilde kullanılabilen optik spektroskopik yöntemler ve gaz kromotografi, iyon mobilite spektrometresi gibi elektronik/kimyasal yöntemler ile hassas kimyasal seçicilik seviyesine ulaşılabilmektedir.

Yığın patlayıcı tespitinde ise cismin içine nüfuz edebilme özelliği sebebiyle radyolojik 1şımalar (Örn: X-ray) ve elektromanyetik dalgalarla metal ve nesne tespiti yıllardır kullanılmaktadır (Aydın ve Yüksel, 2019; Yüksel vd. 2015). Diğer yandan, yoğun biçimde araştırma konusu olan ve uzaktan patlayıc1 tespiti konusunda gelecek vadeden kızılötesi, terahertz, mikrodalga ve radar elektromanyetik görüntüleme yöntemleri bulunmaktadır. Bu yöntemler Şekil 2'de gösterildiği üzere, elektromanyetik (EM) spektrumun büyük bir bölümünü kaplamaktadır. 
El Yapımı Patlayıcıların ve Patlayıcı Maddelerin Tespitinde Kullanılan Spektroskopi Tabanlı Yöntemlerin Karşılaştırılmasına İlişkin Bir İnceleme

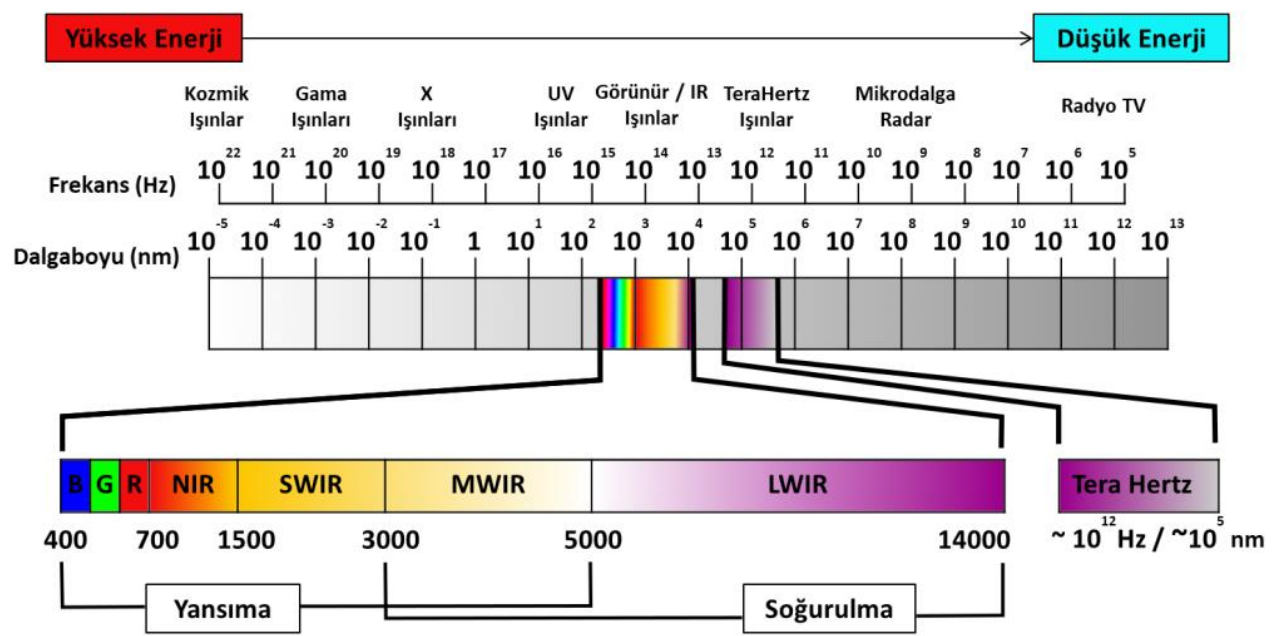

Şekil 2. Elektromanyetik Spektrum. (Gonzalez ve Woods, (2007)'dan Genişletilerek Çizilmiştir.)

Literatürde önerilen tekniklerin bazıları patlayıcı maddelerin moleküler yapısına zarar verebilmektedir. Spektroskopi yöntemiyle EYP tespiti ve teşhisi, çoğu durumda tahribatsız, güvenli ve insan sağlı̆̆ına zarar vermeyen bir teknik olarak öne çıkmaktadır. IR ışınlarının enerjileri oldukça düşük olduğu için, bu enerji, moleküllerin elektronlarını aşırı derecede uyararak başka enerji seviyelerine geçmelerine neden olmamaktadır. Dolayısıyla söz konusu enerji seviyesi, yalnızca molekül içi titreşim ve dönme oluşturabilmektedir. Bu manada, patlayıcı maddelerin parmak izi bölgelerinin tespitinde Terahertz, Raman ve IR spektroskopi gibi teknikler, tahribatsız/zararsız teknikler olarak bilinmektedirler (Day vd., 2004; Grant vd., 2005). Fourier Transform Spektroskopisi (FT-IR) spektroskopisi ayrica, patlayıcı moleküllerin fonksiyonel gruplarının ve parmak izi bölgesine ait bilgilerin ayrıntılı olarak tespit edilmesine olanak sağlamaktır.

Yukarıda bahsi geçen bazı yöntemler EYP'nin topraktan farkını (ör: yere bakan radar), bazısı metal içeriğini (ör: metal dedektör) ararken, bazı yöntemler de EYP içindeki ve üzerindeki patlayıcıyı aramaktadır (ör: LIBS, IR-spektroskopi). İkinci tip yöntemlerde, doğru tespit ve sınıflandırma için patlayıcıların kimyasal yapılarını bilmek önemlidir. Ek’te gösterildiği üzere, bilinen birçok patlayıcı belirli oranlarda azot $(\mathrm{N})$, karbon $(\mathrm{C})$, oksijen $(\mathrm{O})$ ve hidrojen $(\mathrm{H})$ içermektedir (Politzer ve 
Murray, 2014; Stine, 1992). Diğer organik bileşik sınıflarına kıyasla, patlayıcılar azot ve oksijen bakımından zengin, karbon ve hidrojen bakımından fakir olmaları ile karakterize edilirler (Pellegrino vd., 2015). Ancak patlayıcıların en önemli göstergelerinden biri yoğunluklarıdır. Yoğunluk, patlayıcıların içerdikleri moleküllerin kimyasına, kristal yapılarına ve geometrilerine bağlıdır (Venugopalan, 2015). Ek'te verilen Tablo'da, sık karşılaşılan patlayıcıların kimyasal yapıları verilmiştir. Patlayıcı maddelerin tespiti için üzerinde çalışılan yöntemlerden bir kısmı patlayıcıların moleküler bağlarının enerji altındaki dönüşsel ve titreşimsel frekanslarının oluşturduğu parmak izlerini kullanmaktadır. Ancak kimyasal imzalara dayanan tespit sistemlerinin yeteneklerini değerlendirmek için, operasyonel ortamda patlayıcı kalıntılarının kalıcılığı ve kaderi de anlaşılmalıdır. Örneğin, bazı malzemeler foto-bozunmaya uğrayabilir, bazıları çözelti içerisinde bileşenlerine ayrılabilir veya çözücü ile kimyasal reaksiyona girebilir (Kunz vd., 2012; Pellegrino vd., 2015).

$\mathrm{Bu}$ çalışmada yukarıda bahsi geçen görüntüleme yöntemlerinden sıklıkla karşımıza çıkan dört tanesi seçilmiş, avantaj ve dezavantajları ile daha detaylı olarak anlatılmıştır. Seçilen bu yöntemler sırasıyla (i) hiperspektral görüntüleme, (ii) FTIR spektroskopi, (iii) Terahertz ve (iv) LIBS görüntülemedir. Bu yöntemlerin hepsi aslında spektroskopik yöntemler olup, Şekil 1'deki optik yöntemler altına girmektedir. $\mathrm{Bu}$ yönleriyle, aslında birçok bileşenleri ortak olmasına rağmen, kullanımlarının fayda getireceği yerler farklı olarak karşımıza çıkmaktadır.

\section{Hiperspektral Görüntüleme ile Patlayıcı Tespiti}

Hiperspektral görüntüleme aktif ve pasif aydınlatma şartlarında kullanılan bir yöntem olup, uzaktan algılamada önemli bir araştırma alanıdır ( $\mathrm{Pu}$, 2017). Patlayıcı madde ve kalıntılarına müdahale etmeksizin hasarsız biçimde kimyasal tespit gerçekleştirmek için üzerinde çalışılan ve sonuç alınabilen yöntemler arasındadır. Nesnelerin spektral parmak izleri kullanılarak hassas kimyasal seçicilik sağlayabilen bu yöntemin, geniş bir uygulama alanı bulunmaktadır. Hâlihazırda, tarım, ormancılık, jeoloji, çevrebilim gözlemi, afet gözlemi ve gıda gibi pek çok sektörde yaygın olarak kullanılmaktadır. Kullanıldığ 1 sektörde beklenen amaçlar çerçevesinde; fabrikalarda üretim süreçlerinden uçak ve uydulara kadar çeşitli platformlarda farklı model ve tasarımlarla hiperspektral kameralar bulunmaktadır. Fiziksel boyutları sebebiyle platformlar (uydu, uçak vb.) üzerinde kullanılan 
El Yapımı Patlayıcıların ve Patlayıcı Maddelerin Tespitinde Kullanılan Spektroskopi Tabanlı Yöntemlerin Karşılaştırılmasına İlişkin Bir İnceleme

hiperspektral görüntüleme sistemleri, son yıllarda hiperspektral kamera tasarımları ve kızıl ötesi bantta çalışan lazer teknolojisindeki gelişmeler doğrultusunda taşınabilir hale gelmiştir (Jensen, 2015). Gelecekte cep telefonları seviyesinde kullanımının söz konusu olabileceği değerlendirilmektedir.

Hiperspektral görüntüleme yönteminde hem uzamsal hem de spektral görüntünün birlikte işlenmesi avantajı bulunmaktadır. Hiperspektral bir görüntüde her bir piksel içinde yer alan spektral bilgi, tüm kimyasalların kendine has parmak izi ile karşılaştırılarak sınıflandırılma sağlanmaktadır. Fakat bunun yanı sıra, siniflandirma yaparken uzamsal bilgiden de faydalanılmakta ve siniflandirılan cisimlerin fiziksel olarak birbirlerine yakınlıkları da göz önüne alınmaktadır (Bioucas vd., 2013; Plaza vd., 2009).

Sistemin hareket mekanizması bakımından görüntünün elde edilmesi esnasında Şekil 3'te gösterildiği gibi dört farklı yöntem kullanılabilmektedir. Bu yöntemler; nokta tarama (point scanning), çizgi tarama (line scanning), düzlem tarama (plane scanning), tek çekim (single shot) olarak isimlendirilmektedir (Adão vd., 2017). Nokta taramada sistemin dokuma hareketine benzer sekilde hareket ettirilmesi gerekmektedir. Çizgi taramada ise hareketli bir platformdan (uydu ve uçak gibi) süpürme hareketine benzer şekilde veri alınabilmektedir. Düzlem taramada ise, tek çekimden farklı olarak, aynı alan filtre kullanımıyla farklı dalga boylarında ayrı ayrı görüntülenmektedir. Hız bakımından küçük alanlarda tek çekim ve düzlem tarama, çözünürlük ve alan bakımından nokta tarama ve çizgi tarama daha avantajlı olmaktadır (Wang vd., 2017).

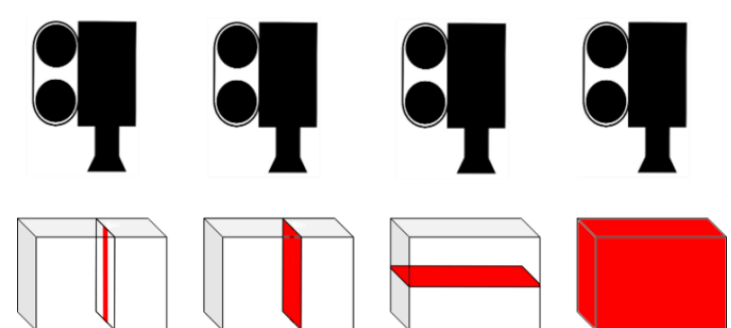

Şekil 3. Sırasıyla Nokta Tarama, Çizgi Tarama, Düzlem Tarama, Tek Çekim (Adão vd., (2017) Çalışmasından Esinlenerek Çizilmiştir.)

Hiperspektral kameralar tarama fonksiyonuna göre değişmekle beraber, yaygın olarak ön optik, çizgisel açıklık, düzeltici optikler, ızgara (grating) ya da prizma ve sensörden meydana gelmektedir. Temsili bir hiperspektral görüntüleme 
sistemi Şekil 4'te yer almaktadır. Ön optik görüntünün toplanmasını ve çizgisel açıklık tarama fonksiyonu ve sensör yapısına göre görüntünün daraltılmasını sağlamaktadır. Düzeltici optikler ise görüntüdeki optik bozulmalarının düzeltilmesini, ızgara ise gelen ışının renk tayfına ayırarak sensör üzerine düşürülmesini sağlamaktadır. Optik teknolojisindeki gelişmeler neticesinde ızgara adı verilen elemanlar ile çok dar dalga boyuna ait bantlar içeren görüntüler toplanabilmekte ve işlenebilmektedir. Artan spektral çözünürlük sonucunda, maddenin daha hassas ayrımının yapılabilmesi avantajı sağlanmaktadır (Sakarya vd., 2015).

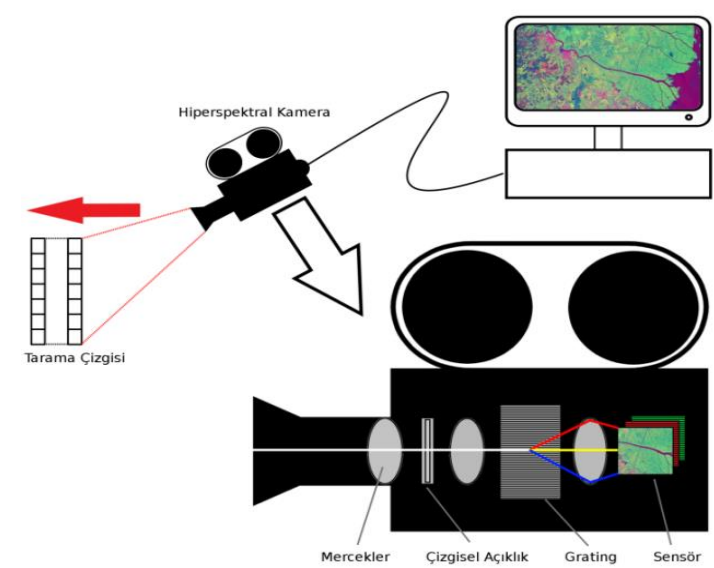

Şekil 4. Temsili Pasif Hiperspektral Görüntüleme Sistemi (Hiperspektral Kameranın İçi Hakkındaki Bilgiler İçin (Korvink vd., 2018)'de Verilen Şematikten Yararlanılmıştır.)

Hiperspektral görüntüleme sisteminde tarama, optik ya da sensör olarak hangi donanım kullanılmış olursa olsun alınan veri uzamsal ve spektral eksenlerden oluşan Şekil 5'te gösterildiği gibi üç boyutlu bir hiperküptür. İlk iki boyut uzamsal bilgiyi gösterirken üçüncü boyut spektral bilgiyi göstermektedir. Hiperspektral bir görüntüde yatay eksende 100'ü aşkın bant, ultraspektral bir görüntüde ise 1000'i aşkın bant bulunmaktadır (Makki, 2017). Ancak, artan bant sayısı verinin boyutlarını dolayısıyla verinin işleme süresini artırmaktadır. 
El Yapımı Patlayıcıların ve Patlayıcı Maddelerin Tespitinde Kullanılan Spektroskopi Tabanlı Yöntemlerin Karşılaştırılmasına İlişkin Bir İnceleme

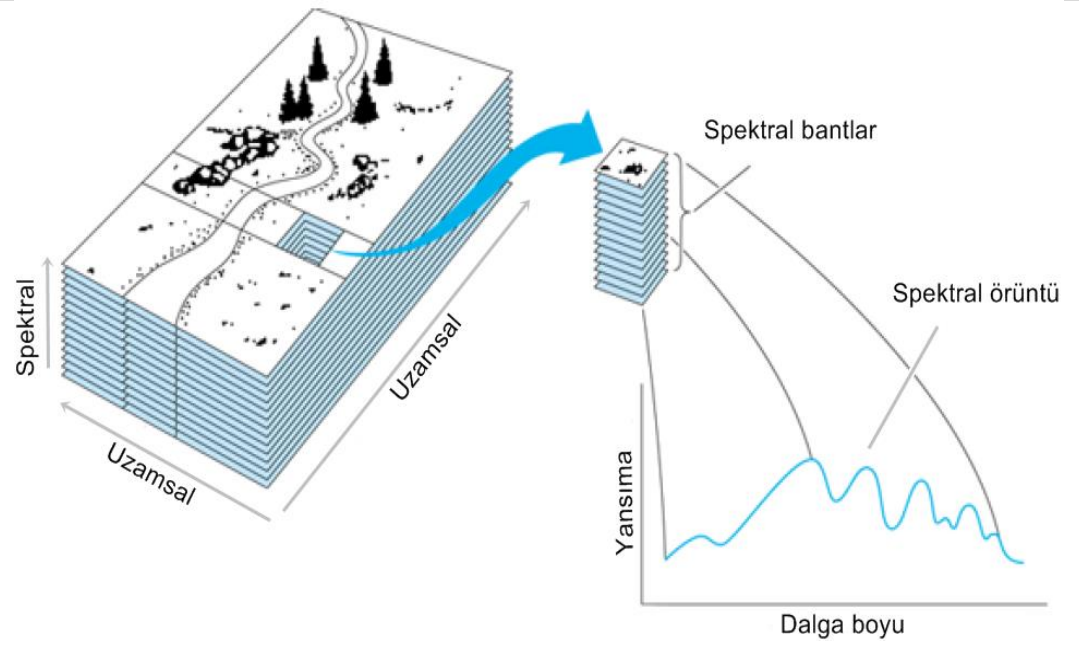

Şekil 5. Hiperküp ve Bir Pikselin Spektral Boyuttaki Gösterimi (Küçük, 2015)

Toplanan karmaşık veri kümesinden değerlendirme yaparak sonuç elde edebilmek için spektral verinin analiz edilmesi ve kimyasalların parmak izlerinin kütüphaneki izler ile karşılaştırılması gereklidir. Gerçek sahada teşhis edilecek madde, mesafe ve çözünürlükle de yakından ilişkili biçimde spektral ve uzamsal olarak diğer verilerle karışık durumdadır. Tam piksel tespiti veya piksel altı hedef tespiti vb. algoritmalarla, veriler saniye/dakika mertebesinde bir sürede işlenebilmektedir (Yüksel ve Karakaya, 2016a; Yüksel vd., 2016b).

Hiperspektral görüntülerin ilave bir kaynak ile aydınlatma yapmadan sadece güneş 1şınlarının yansımalarından elde edilmesine pasif hiperspektral görüntüleme ismi verilmektedir; ilave bir 1şık kaynağ1 kullanıldığında ise aktif hiperspektral görüntüleme denilmektedir. Aşağıda bu tekniklerin avantaj ve dezavantajları tartışılmaktadır.

Pasif Hiperspektral Görüntüleme: Görüntülemenin yapılacağı alana olan uzaklık ve aydınlatmada kullanılması gereken güç göz önüne alındığında, özellikle uydular ve hava platformları için pasif hiperspektral görüntüleme kullanılmaktadır. Hiperspektral görüntüden spektral olarak orman, su ve çatı ayrımının yapılması temsili olarak Şekil 6'da gösterilmektedir. 


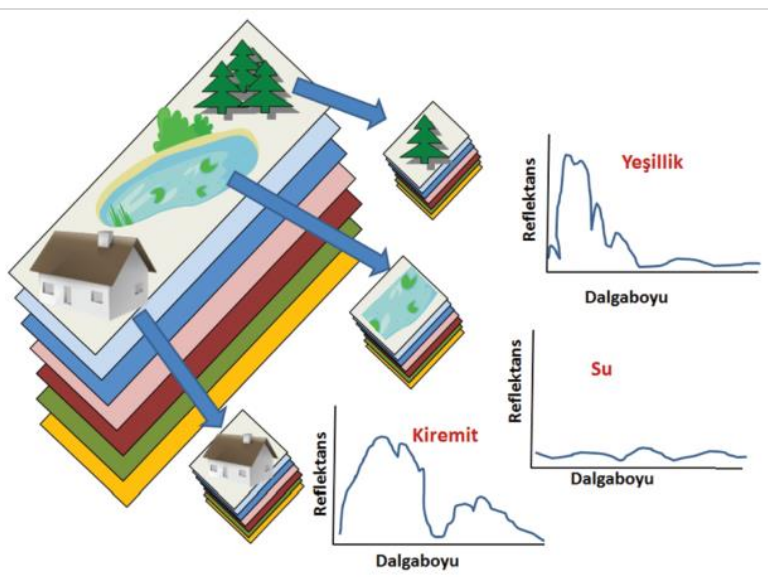

Şekil 6. Pasif Hiperspektral Görüntüleme (Yüksel ve Boyac1, 2018)

Aktif Hiperspektral Görüntüleme: Hedef bölgesinin aydınlatılmasıyla oluşan yansımalardan hiperspektral görüntülerin elde edilmesine aktif hiperspektral görüntüleme ismi verilmektedir. Özellikle de aydınlatmanın lazer ile yapıldığ konfigürasyonlarda, lazerin pek çok molekülün dönüsel ve titreşimsel frekansları ile örtüşmesi sebebiyle kimyasalların tanımlanmasında hız, hassasiyet, temassız ve hasarsız şekilde tespit gibi avantajları mevcuttur (Pellegrino vd., 2015). Son y1llarda lazer teknolojisindeki gelişmeler aktif orta kızılötesi hiperspektral görüntüleme yönteminin laboratuvar dışında sahada kullanılabilmesine imkan sağlamıştır (Fuchs vd., 2007). Kara platformlarında aktif hiperspektral görüntüleme teknolojisi ile belirli bir mesafeden yığın veya iz patlayıcı madde tespiti yapabileceği konfigürasyonlar kurulabilmektedir (Yüksel vd., 2013; Yüksel vd., 2012), el izlerinden patlayıcı tespit edilebilmektedir (De la Ossa vd., 2014). Şekil 7'de bir aktif hiperspektral görüntüleme sistemi ile patlayıcıyla temas etmiş bir insanın elinde kalan patlayıcı kalıntılarının, araç kapısından ya da metal bir plakadan tespitine yönelik grafik yer almaktadır. Günümüzde orta kızı̈ötesi detektör ve kamera teknolojilerinde yaşanan gelişmeler, aktif orta kızılötesi hiperspektral görüntüleme yönteminin etkin kullanımını artırabilecek gelişmeler olarak görülmektedir (Pellegrino vd., 2015). 
El Yapımı Patlayıcıların ve Patlayıcı Maddelerin Tespitinde Kullanılan Spektroskopi Tabanlı Yöntemlerin Karşılaştırılmasına İlişkin Bir İnceleme

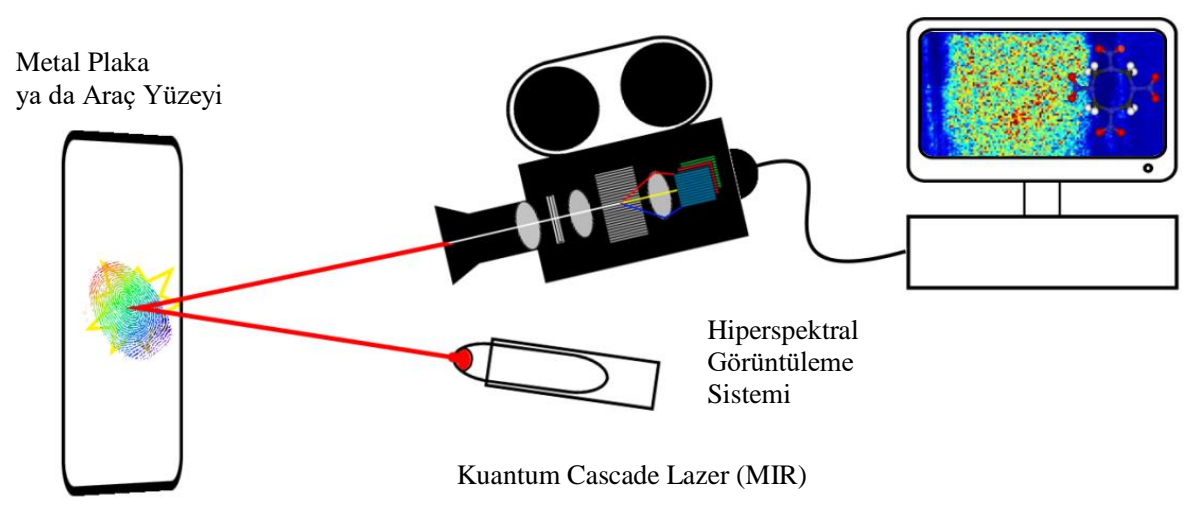

Şekil 7. Aktif Hiperspektral Görüntüleme Sistemi

Literatüre bakıldığında, patlayıcı madde tespiti için geliştirilmiş ve yere konuşlandırılmış (ground-based) birçok hiperspektral görüntüleme sistemi bulunmaktadır (Koz, 2019). Bu çalışmalar içerisinde pasif görüntüleme sistemini ele alan (Bingham vd., 2014; Blake vd., 2009) uzun dalga kızılötesi aralığında, (Nelson vd., 2013; Onat vd., 2009) kısa dalga aralığında veri sağlayacak şekilde çalışmalar yapmışlardır. Elde ettikleri görüntülerden, hedef piksel spektraları ile referans spektraları arasındaki farkları incelemişler; farklı güvenlik mesafelerinden farklı miktarlardaki eser parçacıklarını tespit edilebilmişlerdir. Onat vd., geliştirdikleri sistemin başarım oranını göstermek için ahşap, karton, kot pantolon, naylon, pamuk gibi farklı arkaplan üzerine farklı patlayıc maddeler (AN, HMX, RDX, TATP, TNT) yerleştirmişlerdir. Spektral fark tabanlı bir yöntem kullanarak önerdikleri sistemin seçicilik yeteneğini yani patlayıcı madde tipini tespit etme oranını \%71 olarak bulmuşlardır. Ayrıca hedef tespit oranını entegrasyon süresi başına \%89 ve yanlış alarm olasılığııı \%12 olarak elde etmişlerdir (Onat vd., 2009). Aktif görüntüleme sistemini kullanan (Bernacki vd., 2010; Fuchs vd., 2012) uzun dalga kızılötesinde, (Kumar vd., 2012; Ruxton vd., 2012) kısa ve orta dalga kızılötesi aralıklarında çalışmalar yapmışlardır. Kumar vd., önerdikleri sistemin performansını 5 metreden çektikleri görüntülerdeki TNT, PETN, RDX ve AN piksellerinin spektralarını inceleyerek test etmişlerdir. Ayrıca piksel spektraları arasındaki ilinti katsayısılarını (correlation coefficient) da kullanarak sayısal analiz yapmışlardır (Kumar vd., 2012). Fuchs vd., TNT, PETN, RDX hedef maddeleri tespit etmek için farklı tespit algoritmaları kullanmış ve bu algoritmaların performasını Receiver Operating 
Characteristic (ROC) eğrileri kullanarak karşılaştırmışlardır. En iyi yöntem için son derece düşük yanlış alarm oranlarda \% 80'lik gerçek pozitif oranı elde etmişlerdir.

Hiperspektral Görüntülemenin Avantajları ve Dezavantajları: Pasif hiperspektral görüntüleme ile maden haritalarının çıkarılması, hava kirliliğinin takibi, tarım ürünlerinin analizi gibi geniş ölçekli çalışmalarda hızlı tespit yapılabilmektedir. Hiperspektral görüntüleme sistemi uzaktan tespit ve sınıflandırma yapabilmesi ve uçak, uydu gibi platformlara yerleştirilebilmesi sebebiyle dikkat çekici bir teknoloji olmasına karşın dezavantajları da mevcuttur. Öncelikle hiperspektral görüntüleme yöntemi malzemenin içine nüfuz edememesi, patlayıcıların ise çoğunlukla kapalı ortamlarda bulunması sebebiyle dezavantajlıdır. Hiperspektral görüntülerin bant sayısı ile ilişkili olarak büyük bir veri oluşturması sebebiyle yoğun bir analiz ve algoritma ihtiyacı bulunmaktadır. Pasif hiperspektral yöntemde güneş ışınlarına bağımlılık olması, sadece gündüzleri veri toplanabilmesi sonucunu doğurmaktadır. Toplanan veri doğal engellerden (ağaç vb.) ve güneş 1şınlarının çarpma açısından (gölgeler vb.) etkilenmektedir (Yüksel ve Boyacı, 2018). Bir diğer husus ölçüm mesafesi arttıkça sensör üzerine düşen her bir pikselin daha geniş bir alanı içermesi yani çözünürlükle ilgili olarak alınan verilerin karışması ve hassasiyetin düşmesidir.

Aktif hiperspektral yöntemde lazer ve sensör teknolojinin gelişimine ihtiyaç duyulmaktadır. Deneysel olarak 20 metre mesafeden metal plaka ve araç yüzeyinden miligram seviyesindeki patlayıcı tespiti yapılabileceği görülmektedir. Lazer ile aydınlatarak patlayıcı tespiti yapılan diğer tekniklerle (LIBS vb.) kıyaslandığında insan sağlığına zarar vermeyecek seviyede enerji kullanmas1 sebebiyle avantaj1ı durumdadır (Pellegrino vd., 2015). Ancak lazer kullanımı tespitin kapsamını daraltmakta, şüphe duyulan küçük bir alana doğrultulmasını gerektirmektedir. Aktif hiperspektral görüntüleme, yığın ve eser patlayıcı tespiti, olay yeri inceleme, temassız şekilde açık sahadaki maddenin sınıflandırılabilmesi gibi avantajları barındırmaktadır.

Hiperspektral kamera sistemleri ile patlayıcı madde tespiti yapılabilmesinin çok avantajlı olacağı açıktır. Bu yöntemin başarımının artırılması durumunda, insansız hava araçları ile kullanımı gibi uygulamaları da söz konusu olabilecektir. 
El Yapımı Patlayıcıların ve Patlayıcı Maddelerin Tespitinde Kullanılan

Spektroskopi Tabanlı Yöntemlerin Karşılaştırılmasına İlişkin Bir İnceleme

\section{FT-IR Spektroskopi}

Spektroskopi, EM spektrumda yer alan farklı tipte 1şınların madde ile etkileşiminden ortaya çıkan sonuçları inceleyen bilim dalıdır. Hiperspektral görüntülemeden farkı görüntü olarak değil, tek bir pikselden sonuç alınıyor olması ve de daha çok laboratuvar ortamında çalışıldığından atmosferik ve radyometrik bozunmalara maruz kalmıyor olmasıdır. FT-IR ise, spektroskopinin FT ile hızlandırılmış halidir. Geliştirilmesine 1980'lerde mikro analizler için başlanmış hassas, güvenli ve hızlı bir tekniktir (Naumann, 2000).

Bir FT-IR sisteminin yapısı Şekil 8'de verilmektedir. Buradaki interferometre, bir kızılötesi ışını ikiye bölen ve belirli bir yol farkı sonrası ayrılan iki ışını tekrar birleştirebilen ve sonuç olarak bu iki ışının yoğunluğu arasındaki farkı, yolların arasındaki farkın bir fonksiyonu olarak ölçen bir dedektöre ileten bir cihazdır (Griffiths ve Haseth, 2007). Kaynaktan çıkan kızılötesi 1şın kümesi, interferogramdan geçerek örnek üstüne yönlendirilir. Burada, kullanılan örneğin özelliğine göre 1şık yansır veya geçirilir ve detektör tarafından algılanır. Ölçülen sinyal sayısallaştırılır ve bilgisayara gönderilir. Sonuçta, IR spektrum çizilir ve kaydedilir (Beşergil, 2019).

EM spektrumun IR bölgesi $14000 \mathrm{~cm}^{-1}$ ile $10 \mathrm{~cm}^{-1}$ arasına işaret eder. $\mathrm{Bu}$ bölge yakın dalgaboylu IR $\left(4000 \sim 14000 \mathrm{~cm}^{-1}\right)$, orta dalgaboylu IR $\left(400 \sim 4000 \mathrm{~cm}^{-1}\right)$ ve uzak dalgaboylu IR bölge (10 400 $\left.\mathrm{cm}^{-1}\right)$ olarak üçe ayrılır (Skoog vd., 1998). Bir maddenin kimyasal yapısı hakkında bilgiler içeren spektrumdaki $3600-1200 \mathrm{~cm}^{-1}$ aralığına, "fonksiyonel grup" bölgesi denilir. İkinci nitelikli bölge ise "parmak izi" bölgesi olarak tanımlanan ve maddeye has bilgiler içeren $1200-700 \mathrm{~cm}^{-1}$ bölgesidir (Kılıç ve Karahan, 2010). Parmak izi bölgesi olarak adlandırılan bölge (orta IR bölgesi), özellikle patlayıcı maddelerin tespiti için kullanılabilir. Patlayıcı bileşiklerde bulunan $\mathrm{NO}_{2}$ yapısından kaynaklanan emilimler, karakteristik bir imza gösterirler. $\mathrm{NO}_{2}$ yapıların eğilme ve gerilmelerine karşılık gelen emilimler, iyi seviyede tanımlanmış tespit edilebilen frekanslara sahip olmasının yanında, patlayıcıların IR spektrumunda en güçlü piklere sahip olanlarıdır (Yinon, 1999). 


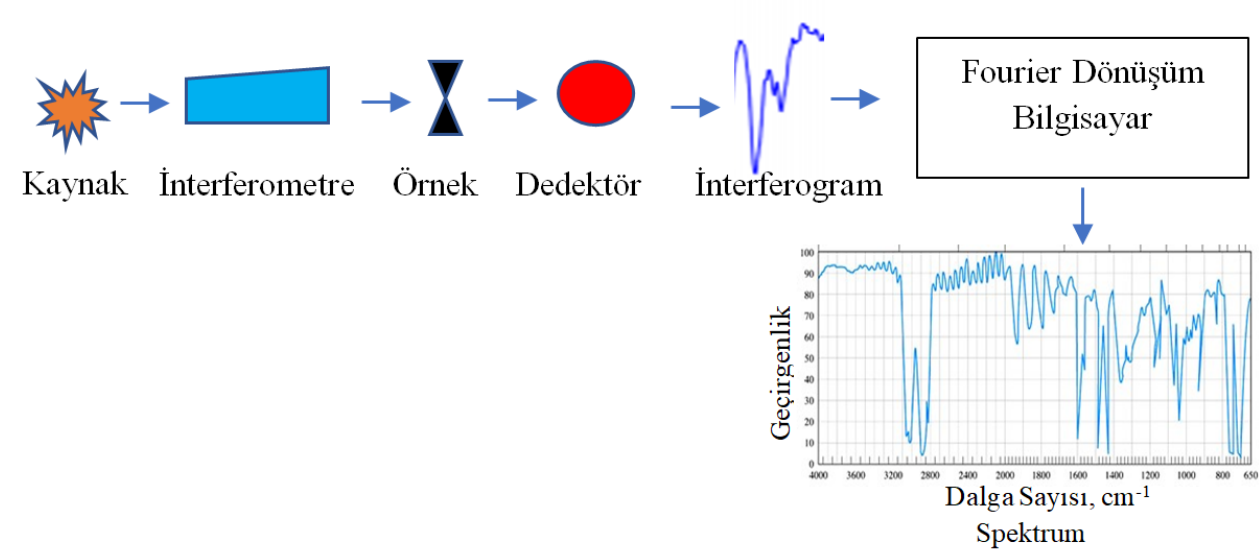

Şekil 8. Bir Örneğin Analiz Süreci (Griffiths vd., (2007) Çalışmasından Esinlenerek Çizilmiştir.)

Fonksiyonel grup bölgesi, bir patlayıcının kimyasal yapısı hakkındaki bilgileri içerir. Bir maddenin IR spektrumundaki piklere bakılarak, karbon, hidrojen ve oksijen bağları arasındaki bilgileri çözümlemek mümkündür. Örneğin, 4000-2500 $\mathrm{cm}^{-1}$ arası tek bağ bölgesidir ve hidrojen bağl1 tekli bağların soğrulduğu bölgedir. OH gerilmesi $3700-3600 \mathrm{~cm}^{-1}$, C-H gerilmesi $3000-2850 \mathrm{~cm}^{-1}$ aralığında gözlenir. Benzer şekilde 2500-2000 $\mathrm{cm}^{-1}$ arası üçlü bağ bölgesidir. Buradaki piklere bakarak $\mathrm{C} \equiv \mathrm{C}, \mathrm{C} \equiv \mathrm{N}$ gerilmesi vardır demek mümkündür. $2000-1500 \mathrm{~cm}^{-1}$ aralığı da çift bağ bölgesi olarak bilinir. IR spektrumda karbon bağların gözlemlemek nispeten daha kolaydır (Beşergil, 2019).

Parmak izi bölgesi bağ yapılarından kaynaklanan dönme, makaslama, gerilme ve bükülme titreşimlerinin gözlendiği bölgedir ve parmak izi bölgesinden alınan sinyaller her patlayıcı maddenin kendine hastır. Bu nedenle, kimyasalların teşhisinde ve tanımlanmasında bu bölgeden faydalanılır (Faust, 1997). TNT, RDX, PETN gibi birçok patlayıcı maddelerin, bu kimyasalların sentezlenmesi ile oluşturulan EYP'lerin ve güçlendirici, itici, yanıcı maddelerin orta IR spektrumları birçok literatürde mevcuttur (Iqbal vd., 1972; Paula, 2016).

FT-IR Spektroskopinin Avantaj ve Dezavantajları: IR analizlerde, molekülde emilen veya molekülden geçen 1şının miktarı belirlenerek, çeşitli kimyasal maddelerin tür tayini gerçekleştirilebilmektedir. FT-IR'ın en önemli 
El Yapımı Patlayıcıların ve Patlayıcı Maddelerin Tespitinde Kullanılan

Spektroskopi Tabanlı Yöntemlerin Karşılaştırılmasına İlişskin Bir İnceleme

avantajları; hızı, hassasiyeti, basit kullanımı ve yüksek sinyal/gürültü oranıdır. Güvenlik güçlerimize karşı sıkça kullanılan patlayıcı türlerinin kimyasal yapıları incelendiğinde, FT-IR spektroskopi yöntemi ile patlayıcıların parmak izleri kolayca tespit edilebilmektedir. Ancak, FT-IR spektroskopi daha çok laboratuvar tipi cihazlarda kullanılmaktadır. Numune miktarının az olması düşük emilimlere yol açtığından, patlayıcı tespit kalitesi ve tespit edilebilen patlayıcı oranı azalmaktadır. Ayrıca, bir EYP olayı sonrası kirletilmiş alandan alınan örneklere ait spektrumlarda, alanda bulunan diğer yapılara ait farklı piklere ve sonuçlara rastlanabilmektedir. $\mathrm{Bu}$ durum, laboratuvar analizini gerçekleştiren işletmenin bu konuda tecrübeli ve dikkatli olmasını, çok kapsamlı bir kütüphane oluşturmuş olmasını ve iyi bir yapay zekâ yazılımına sahip olmasını gerektirmektedir.

\section{Terahertz Spektroskopi}

Terahertz (THz), Şekil 2'de gösterildiği gibi EM spektrumda mikrodalga ile kızılötesi bölgeleri arasında kalan, bir yanında elektronik, diğer yanında fotonik 1şınımlar mevcut olan, 0,1-10Thz arasındaki alandır. $1 \mathrm{THz}=10^{12} \mathrm{~Hz}$ 'dir. Bu alan, yakın zamana kadar, uygun $\mathrm{THz}$ üreteçleri üretilemediğinden kullanılamamakta ve $\mathrm{THz}$ boşluğu adını almaktaydı. Şimdilerde ise ilerleyen donanım yapısıyla, aktif veya pasif $\mathrm{THz}$ görüntüleme yapılabilmekte ve tarım ürünlerinin tahribatsız kalite kontrollerinden bilişim ve haberleşme teknolojilerine birçok alanda, zararsız tıbbi görüntülemede, biyoloji ve sağlı bilimlerinde, patlayıcı madde tespitinde ve algılanmasında, kriminal alanlarda uyuşturucu ve silah tespit edilmesinde kullanılabilmektedir (Davies vd., 2008).

$\mathrm{THz}$ alanındaki gelişmelerin hızla yayılmasının şüphesiz ki ilk nedeni $\mathrm{THz}$ dalgalarının karton, plastik, deri, kumaş, tahta, kağıt, karton gibi metalik olmayan, kuru maddelerden geçebilmesidir (Pellegrino vd., 2015). Bunun yanısıra, THz görüntüleme moleküllerdeki veya moleküller arasındaki titreşimlere bağlı olarak oluşmakta ve dolayısıyla $\mathrm{THz}$ ışınımı bazı maddelerde parmak izi özelliği göstermektedir. Örneğin TNT, RDX, SEMTEX, HMX, PETN, Tetril gibi bazı patlayıc kimyasal maddeler $\mathrm{THz}$ spektroskopi vasıtayla tespit edilebilmektedir. $\mathrm{THz}$ dalgalarının üçüncü özelliği, düşük enerji seviyelerine sahip olmalarıdır. Bu nedenle de THz ışımlarının insan sağlığına zararı bulunmadığı söylenmektedir (Ergün ve Sönmez, 2015). Ayrıca 3 THz altındaki frekans boşluğunda, FT-IR spektroskopiye 
kıyasla yüksek bir sinyal-gürültü oranına sahip olması nedeniyle daha avantajlı olarak kabul edilmektedir (Leahy-Hoppa vd., 2009).

$\mathrm{Bu}$ özellikler sayesinde, sanayide ve endüstriyel alanda kullanılan birçok ambalaj malzemesinin arkasındaki nesneler görülebilmekte ve üzerleri plastik, kumaş vb. materyallerle kaplı dahi olsa, içlerindeki patlayıcıları tespit etmek mümkün olabilmektedir. Kamu kurum ve kuruluşlarında, postanelerde, hava limanlarında, zarf ve valizler tahribatsız olarak muayene edilebilmektedir (Ergün ve Sönmez, 2015; Ueno ve Ajito, 2008) İlave olarak, THz teknolojisinin toprak altında gömülü halde bulunan mayın ve metal parçalarını tespit edebildiğine dair çalışmalar da yapılmış ve mayın tespiti ve tanımlanmasında da kullanılabileceği ortaya koyulmuştur. Fakat derinlik arttıkça görüntünün çözünürlügü büyük oranda düşmektedir (Zhong, 2004).

THz bandının yüksek frekans bantları patlayıcılar için daha yüksek seçicilik sunarken, laboratuvar ortamından teoriğe geçişte ciddi sıkıntılar barındırmaktadır. Nispeten zayıf ve geniş alana yayılmış patlayıcı özellikleri, atmosferik su buharı emiliminden dolayı zayıflamakta ve hem giysiden hem de hedef patlayıcılardan olan saçılmaların birleşik etkilerinin ölçülmesiyle maskelenmektedir. Dolayısıyla da günümüzde THz kullanımı daha çok atmosferik olaylardan etkilenmeyecek şekilde, çok-yakın algılama mesafesinde yapılmaktadır.

$\mathrm{THz}$ 1şınımlarının atmosferde yayılırken zayıflaması ve soğurulması görüntülemede kullanılması planlanan bandın belirlenmesinde etkili olmaktadır. Özellikle, uzaktan görüntüleme yapılacaksa atmosfer şartlarında zayıflamanın düşük olabileceği bölgelerde yapılması gerekmektedir. $0,1 \mathrm{THz}$ ile $1 \mathrm{THz}$ arasındaki bölgelerde atmosfer ortamında daha az zayıflaması nedeniyle uzaktan algılama için daha uygun olarak kullanılabilir (Kemp, 2011; Tekbaş, 2014).

Sonuç olarak, bir Terahertz spektroskopi sisteminin daha düşük frekanslarda çalışmak, daha iyi çözünürlüğe sahip olmak, portatif sistemler olmak, insan sağlığına zarar vermemek gibi çeşitli avantajları vardır. Bunun yanısıra, ışın kaynağının gücünü ve dedektörlerin duyarlılı̆̆ını arttıracak, bu sayede de daha iyi sinyal-gürültü oranı elde edilmesine imkân verecek şekilde donanım üzerine araştırmalar devam etmektedir. Günümüzde Terahertz görüntülemenin takıldığı engellerden biri de görüntülerin gerçek zamanlı kullanılamayacak kadar uzun bir zamanda elde edilmesi 
El Yapımı Patlayıcıların ve Patlayıcı Maddelerin Tespitinde Kullanılan Spektroskopi Tabanlı Yöntemlerin Karşılaştırılmasına İlişkin Bir İnceleme

olarak görülmektedir. Bu tekniğin, günümüzde mevcut teknoloji ile kullanılabilir bir teknoloji olması muhtemelen kullanımı için en önemli kuvvet çarpanıdır. Ancak teknik kullanılırken, patlayıcı maddelerin spektrumunu elde etmek adına doğru ve güvenilir bir veritabanı elde edebilmek için en uygun yöntemler tercih edilmelidir (Leahy-Hoppa vd., 2009).

\section{Lazer Etkileşimli Plazma Spektroskopisi (LIBS)}

Lazer etkileşimli plazma spektroskopisi (Laser induced breakdown spectroscopy - LIBS), teorikte yığın miktardaki patlayıcıları, yüzeylerdeki patlayıcı kalıntılarını, buhar biçimindeki patlayıcıları veya bu patlayıcıları barındıran kara mayınlarını tespit etmek için kullanılabilen bir tekniktir. Bu teknikte, hedefe güçlü bir lazer darbesi yansıtılmakta ve hedef üzerinde oluşan plazmadan yansıyan optik sinyaller spektroskop ile ölçülmektedir.

Bu tekniğin temelini, Şekil 9'da gösterildiği gibi atomik emisyon çizgilerine bakarak moleküllerin tanınabilmesi oluşturmaktadır.

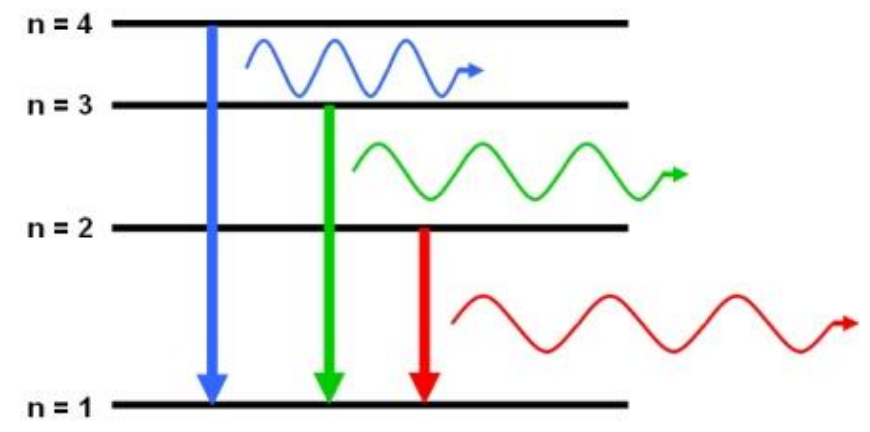

Şekil 9. Atomik Emisyon Çizgileri (n: Enerji Seviyeleri ve Enerji Seviyelerindeki Geçişlerde Oluşan Işımalar) (www.astronomy.swin.edu.au)

Her element, görünür spektrumda farkl1 atomik emisyona sahiptir. Geniş bantlı bir spektrometre yardımıyla, lazer tarafından üretilen plazmadaki tüm element spektrumları yakalanabilir. Daha sonra da atomik emisyon çizgileri ve atomik emisyon çizgilerinin yoğunluğu numuneyi tanımlamak için kullanılmaktadır. Günümüzde LIBS, plastikler, biyolojik malzemeler ve diğer organik bileşikler gibi metallerin dışındaki çeşitli malzemelere uygulanabilmektedir. Karbon, oksijen, 
hidrojen ve azot atomik emisyon çizgileri çoğunlukla organik molekülleri tanımlamak için kullanılmaktadır.

LIBS, hedef maddeden atomik emisyon eldesi için lazerle üretilen bir plazma veya kıvılcım kullanan kimyasal analiz şeklidir (Pellegrino vd., 2015). Bir plazma, yüklü türlerin topluca hareket ettiği atom ve iyonlardan oluşur. Atomik emisyonda, plazmadaki uyarılan atomların ve tek atomlu iyonların daha düşük enerji düzeylerine geçişlerinde yaptıkları ultraviyole, kızılötesi ve görünür bölge 1şımasının ölçülmesi, yaygın olarak kullanılan spektroskopi yönteminin temelini oluşturur. Tek bir lazer atışıyla veri analizi bir saniye içinde yapılabilir. Standart bir LIBS sistemi, 1şını oluşturacak lazer ekipmanı, ışını hedef maddeye taşıyacak optikler (mercekler aynalar vs.), hedef üzerinde oluşan plazma ışımasını toplayıp spektroskopa götürecek toplayıcı optikler ve elde edilen veriyi işleyecek bilgisayarlardan oluşur. Bu sistemin genel işleyişi Şekil 10'da gösterilmiştir. Odak noktasındaki lazer gücü $-1 \mathrm{GW} / \mathrm{cm}^{2}$ yi aştı̆̆ında, bir mikroplazma oluşturulur. Plazmadan yayılan emisyon daha sonra bir dizi mercek tarafindan toplanır ve toplanan 1şığı çözmek için bir spektrometreye iletilir. Son olarak, spektral olarak çözünen 1şık, bir LIBS spektrumu oluşturmak için bilgisayarda işlenir (Munson vd., 2007).

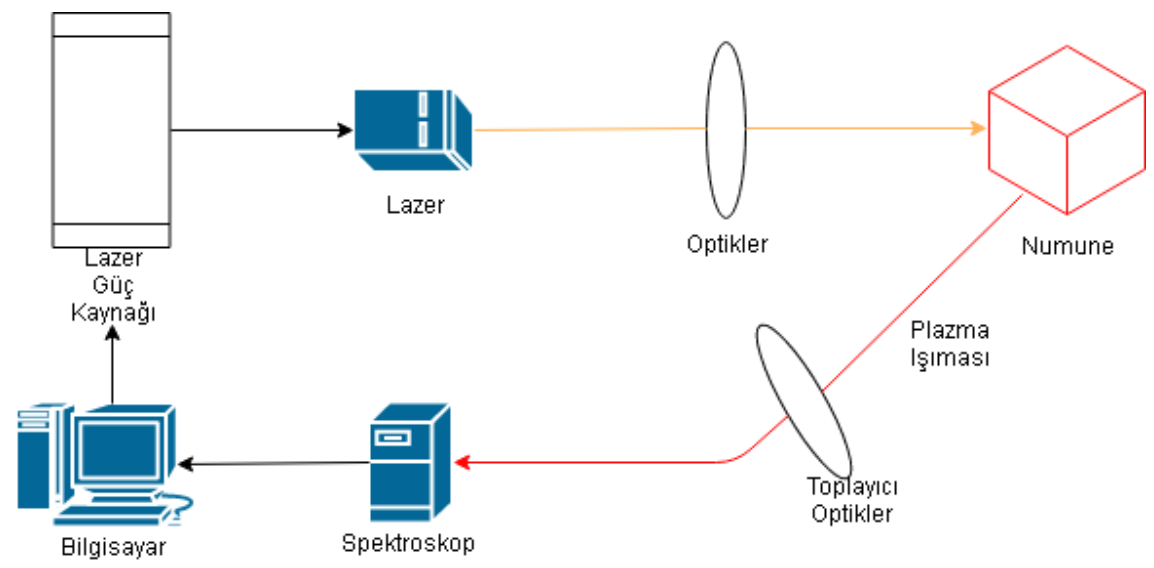

Şekil 10. LIBS Ekipmanının Çalışma Prensibi

(Pellegrino vd., (2015)'den Esinlenerek Çizilmiştir.) 
El Yapımı Patlayıcıların ve Patlayıcı Maddelerin Tespitinde Kullanılan

Spektroskopi Tabanlı Yöntemlerin Karşılaştırılmasına İlişkin Bir İnceleme

Bir tespit tekniği olarak LIBS birçok avantaja sahiptir ve sağlık, gıda, uzay araştırmaları ve başka güvenlik uygulamalarında kullanılmaktadır (Anzano vd., 2000; Elsherbiny ve Nassef, 2015, Hybl vd., 2003; McCanta vd., 2013; Portnov vd., 2003). LIBS, karbon, hidrojen, oksijen ve azotun atomik emisyon çizgilerini tanımlayabildiğinden, prensip olarak, yığın halindeki patlayıcıları, yüzeylerdeki patlayıcı kalıntılarını ve buhar haldeki patlayıcıları tespit etmek için kullanılabilir. Karbon, hidrojen, oksijen ve azot elementlerinin birbirlerine olan nispi oranları patlayıcılar için farklı imzalar oluşturur.

Ortamdaki patlayıcı miktarı milyon partikülde bir veya milyar partikülde bir olduğu için farklı mokelüllerin aynı ortamda bulunmasıyla ölçüm zorlaşmaktadır. Patlayıcıların diğer organik malzemelerden ayrılması için detaylı analiz yapılması gerekir. LIBS ile patlayıcı tespiti ayrıca, kimyasalın tipine ve örneğin bulunduğu yüzey durumuna ve lazerin enerjisi, darbe genişliği, dalga boyu, spektrometrenin etkinliği ve hedefe olan mesafe gibi deneysel faktörlere de bağlıdır. Junjuri ve arkadaşları 5 ayrı patlayıcıyı $532 \mathrm{~nm}$ Nd:YAG lazeri kullanılan LIBS ekipmanıyla test etmişlerdir (Junjuri vd., 2017). Gottfried ve arkadaşları da LIBS tekniğini kullanarak anti personel mayınlarını incelemişlerdir (Gottfried vd., 2009). Moros ve arkadaşları mektup zarfları üzerine sürülmüş ammonal, RDX, TNT ve chlorotite gibi patlayıcı maddeleri ve ölçümü bozabilecek diğer zararsız organik maddeleri tespit etmişlerdir (Moros vd., 2010). Wang ve arkadaşları da LIBS görüntülemede makine öğrenmesi yöntemlerini araştırmışlardır (Wang vd., 2019).

LIBS ile Patlayıcı Tespitinde Avantaj ve Dezavantajlar: LIBS sistemlerinin avantajları aşağıdaki gibidir (Pellegrino vd., 2015): LIBS için ayrı bir örnek hazırlanması gerekmez; lazer ışınları uzaktan hedefe yansıtılıp, bir nokta üzerinden ölçüm alınır. Analiz sonuçları hızlıdır. LIBS spektrumu, patlayıcıların yanısıra, kara mayınlarında veya EYP'lerde kullanılan malzemeler hakkında da bilgi içerebilir. Böylece patlayıcı imzaların yanısıra ikincil optik imzalar da elde edilmiş olur. LIBS sistemlerini isterlere göre elde taşınır veya uzak mesafeden veri alır şekilde tasarlamak mümkündür.

$\mathrm{Bu}$ avantajlarının yanısıra, LIBS ile çalışırken bazı noktalarda dikkatli olmak gerekmektedir. LIBS nokta bazlı çalıştığı için, geniş bir alanı taramaktansa sadece hedefteki birkaç mikron kalınlığındaki noktadan ölçüm alınmaktadır. Dolayısıyla ya lazerin hedefin üzerine direkt gelmesini sağlamak ya da birçok örneklem almak 
gerekmektedir. LIBS lazeri güçlüdür, her ne kadar "tahribatsız yöntem” olarak adlandırılsa da hedef materyal üzerinde hasara yol açar. Bu yüzden yeni bir ölçüm yapılacaksa, ölçümün doğru çıkması için materyal üzerinde başka bir nokta seçilmelidir. Bunun yanı sıra LIBS, plazmayı oluşturmak için güçlü lazer darbeleri kullanır; lazer darbeleri cilt ve göz için tehlikeli olduğundan güvenlik koşulları dikkate alınmalıdır. Kullanan personelin, aletin ve hedefin etrafındaki doğrudan gelen veya yansıyan lazer 1şığından uygun şekilde korunmasını sağlamak için önlemler alınmalıdır. LIBS için kullanılan dalga boyu daha çok göz için tehlikeli olan 200-1000 nm arasında olduğundan, özellikle de göz sağlığına dikkat etmek gerekmektedir. Bunun yanı sıra, bazı patlayıcı kimyasalların (örneğin, benzin, metan vb.) buharından korunmak için de gereken önlemler alınmalıdır.

Dezavantaj1 avantaja dönüştürürsek, LIBS, nokta örnekleme kabiliyeti nedeniyle nanogram kadar küçük patlayııı izlerini tanımlayabilir. Araçların kapı kollarında, gövde kapaklarında, nakliye araçlarının yüzeylerinde bulunabilecek patlayıcı kalıntılarını tespitte kullanılabilir. Burada yine kritik nokta, lazerin bu patlayıcı kalıntısına isabet etmesinin nasıl sağlanacağıdır. Dahası, aynı elementleri içeren patlayıcı ile diğer zararsız organik madde türlerinin ("karıştırıcı" olarak da bilinir) aynı ortamda bulunması, patlayıcı maddenin ayırt edilmesini zorlaştırabilir (TNT ve benzin gibi yakıtlar). Ve elbette hedef üzerindeki lazer darbesi gözle görülür hasara neden olabildiğinden, canlılar üzerinde kesinlikle kullanılmamalıdır.

$\mathrm{Bu}$ çalışma kapsamında patlayıcı madde tespitinde kullanılan yöntemler detaylı bir şekilde incelenmiş, dört spektroskopi tabanlı yöntemin üstün geldikleri ve eksik kaldıkları noktalar ayrıca Tablo 1'de özetlenerek sunulmuştur.

\section{Analiz}

Özellikle son yıllarda asimetrik bir silah olarak karşımıza çıkan EYP ve diğer patlayıcı maddelerin terör unsurlarınca yoğun şekilde kullanımı, bu eylemlere karşı tedbir alınmasını kaçınılmaz kılmaktadır. Bu amaçla, burada yazabildiğimiz ve yazamadığımız (ör: Raman ve İyon Mobilite Spektroskopileri) birçok spektroskopik teknikte önemli ilerlemeler kaydedilmektedir. Buna karşın, askerî ve ticari amaçla kullanılanların yanında, kolayca sentezlenebilen binlerce patlayıcı bileşik vardır ve her bir bileşiği istenilen seviyelerde tespit edebilen tek bir yaklaşım bulunmamaktadır. Ancak, araştırma gruplarının ve şirketlerinin sayısı her geçen gün 
El Yapımı Patlayıcıların ve Patlayıcı Maddelerin Tespitinde Kullanılan Spektroskopi Tabanlı Yöntemlerin Karşılaştırılmasına İlişkin Bir İnceleme

artmakta ve görünüşte imkânsız görünen hedeflerin gerçekte ulaşılabilir olabileceğine dair büyük çalışmalar yürümektedir. Bu çalışmanın amacı, bu sürecin başarılı bir şekilde sonuçlanmasına yardımcı olma yolunda bir adım atabilmektir.

Tablo 1. Karşıllaştııılan Yöntemlerin Avantaj ve Dezavantajlarına Genel Bakış

\begin{tabular}{|c|c|c|}
\hline Yöntem & Avantajlar & Dezavantajlar \\
\hline $\begin{array}{l}\text { Hiperspektral } \\
\text { görüntüleme }\end{array}$ & $\begin{array}{l}\text { Geniş ölçekli uygulamalar için hızlı } \\
\text { tespit imkanı verir. } \\
\text { Farklı platformlardan (Sabit yer, uydu ve } \\
\text { uçak) veri sağlar. } \\
\text { Piksel seviyesinde maddelere has } \\
\text { spektral imzalar üretebildiği için } \\
\text { sınıflandırma uygulamalarında başarımı } \\
\text { oldukça yüksektir. } \\
\text { Nanogram kadar küçük patlayıcı izlerini } \\
\text { tanımlayabilecek kabiliyettedir. }\end{array}$ & $\begin{array}{l}\text { Kapalı malzemelerin içine nüfuz } \\
\text { edemez. } \\
\text { Bir ışık kaynağına (güneş veya harici) } \\
\text { ihtiyaç duyar. } \\
\text { Ölçüm mesafesine bağlı bir şekilde } \\
\text { veride karışım pikselleri oluşabilir. } \\
\text { Nanogram seviyesindeki patlayıcıları } \\
\text { tespit etmek için en çok } 10-20 \mathrm{~cm} \\
\text { uzakta olunması gerekir. }\end{array}$ \\
\hline $\begin{array}{l}\text { FT-IR } \\
\text { spektroskopi }\end{array}$ & $\begin{array}{l}\text { Herhangi bir yapıdaki maddenin (sıvı, } \\
\text { toz, gaz vb.) numunesi üzerinden analiz } \\
\text { imkanı sağlar. } \\
\text { Patlayıcıların parmak izlerini hızlıca ve } \\
\text { yüksek doğrulukla tespit edebilmektedir. }\end{array}$ & $\begin{array}{l}\text { Laboratuvar tipi cihazlarda kullanımı } \\
\text { yaygındır. } \\
\text { Patlayıcı tespit başarımı numune } \\
\text { miktarı ile ilintilidir. }\end{array}$ \\
\hline $\begin{array}{l}\text { Terahertz } \\
\text { spektroskopi }\end{array}$ & $\begin{array}{l}\text { Düşük frekanslarda çalışma imkanı } \\
\text { sunar. } \\
\text { THz dalgaları insan sağlı̆̆ına zarar } \\
\text { vermez. } \\
\text { Maddelere nüfuz edebildiğinden gizli } \\
\text { maddeleri tespit edebilmektedir. }\end{array}$ & $\begin{array}{l}\text { Gerçek zamanlı uygulamalar için } \\
\text { uygun değildir. } \\
\text { Yüksek sinyal-gürültü oranı elde } \\
\text { etmek için güçlü 1şık kaynağına ihtiyaç } \\
\text { duymaktadır. }\end{array}$ \\
\hline LIBS & $\begin{array}{l}\text { Uzak mesafeden veri alımına uygundur. } \\
\text { Analiz sonuçları hızlıdır. } \\
\text { Nanogram kadar küçük patlayıcı izlerini } \\
\text { tanımlayabilecek kabiliyettedir. }\end{array}$ & $\begin{array}{l}\text { Hedef materyal üzerinde hasara yol } \\
\text { açabilir. } \\
\text { Lazer darbeleri cilt ve özellikle göz } \\
\text { için tehlikelidir. Uygun korunma } \\
\text { şartlarının alınması gerekir. }\end{array}$ \\
\hline
\end{tabular}


Seniha Esen YÜKSEL, Sefa KÜÇÜK, Vedat TEKELİ, Birol KILIÇ, R.Hamza KARAKAYA, Murat Berkay ZEKA

$\mathrm{Bu}$ çalışmada, patlayıcı tespitinde kullanılabilecek dört yöntem incelenmiştir. Görüldüğü üzere, patlayıcı madde tespitinde kullanılabilecek her teknolojinin avantaj ve dezavantajları bulunmaktadır. Tespit etmeyi arzuladığımız patlayıcı maddenin cinsine, mesafesine, zemin altındaki derinliğine, bileşenlerine, teknolojinin kullanılacağı çevre ve ortam şartlarına, ihtiyaç duyulan hassasiyete, hız ve mesafeye göre bir yöntem tercih edilmesi gerekmektedir.

Aktif ya da pasif hiperspektral görüntüleme sisteminin, patlayıcı madde ve kimyasallarının tespitinde sağlayabileceği avantajlar sebebiyle gelecek vadeden bir teknoloji olarak değerlendirilebileceği görülmektedir. Hiperspektral görüntüleme yöntemi farklı sektörlerde pek çok uygulamasıyla fiilen kullanılmaktadır. Sistem tasarımlarının boyutlarının küçülmesi, üretimin artması ve maliyetlerin azalması ile kullanımı yaygınlaşacaktır. Dolayısıyla hiperspektral görüntüleme yöntemi kimyasal madde tespitinin bireylerce bile yapılabilmesine imkân sağlayabilecek potansiyeli barındırmaktadır.

Aktif ya da pasif hiperspektral görüntüleme sisteminin, patlayıcı madde ve kimyasallarının tespitinde sağlayabileceği avantajlar sebebiyle gelecek vadeden bir teknoloji olarak değerlendirilebileceği görülmektedir. Hiperspektral görüntüleme yöntemi farklı sektörlerde pek çok uygulamasıyla fiilen kullanılmaktadır. Sistem tasarımlarının boyutlarının küçülmesi, üretimin artması ve maliyetlerin azalması ile kullanımı yaygınlaşacaktır. Dolayısıyla hiperspektral görüntüleme yöntemi kimyasal madde tespitinin bireylerce bile yapılabilmesine imkân sağlayabilecek potansiyeli barındırmaktadır.

Pasif hiperspektral görüntülemenin gözle algılanması zor olan kamuflajlı hedeflerin tespiti, varsa açık sahadaki büyük ölçekli patlayıcıların tespiti, terörün finans kaynaklarından biri olan uyuşturucu hammaddesi hint keneviri tarlalarının tespiti maksadıyla insanlı ya da insansız hava platformları da dâhil olmak üzere kullanılabileceği öngörülmektedir. Aktif hiperspektral sistemlerin teknolojik olarak olgunlaşması durumunda ise açığa çıkarılan patlayıcıların cinsinin hasarsız tespiti ve olay mahalli incelemeleri ya da TSK'nın diğer lojistik ve harekât ihtiyaçlarında analiz maksatı kullanılabileceği kıymetlendirilmektedir. Ancak hâlihazırda gömülü patlayıc1 veya EYP'lerin tespitinde kullanılabilirliği zayıf olarak değerlendirilmektedir. 
El Yapımı Patlayıcıların ve Patlayıcı Maddelerin Tespitinde Kullanılan

Spektroskopi Tabanlı Yöntemlerin Karşılaştırılmasına İlişkin Bir İnceleme

FT-IR spektroskopi tekniği ile farklı kimyasal yapılara sahip patlayıcı türlerin spektrumları hem kimyasal açıdan hem de fonksiyonel açıdan incelenebilmektedir. FT-IR spektroskopi tekniğinin, yeterli spektral veri tabanlarının oluşturulması ile güvenlik alanında yaygın olarak kullanılan ucuz ve önemli bir tespit yöntemi haline gelmesi kuvvetle muhtemel olacaktır.

THz dalgalarının insan sağlığına zararsız olması, insan vücudu üzerinde olumsuz etkilerinin X-1şınlarına göre yok denecek kadar az olması ve maddelerin ve materyallerin içinden geçebilmesi ve maddelere nüfuz edebilmesi açısından, gizli maddeleri tespit edebilmesi gibi özellikleri sayesinde bu teknoloji son ylllarda ilgi odağı haline gelmiş ve bu alanda çalışmalar hız kazanmıştır. Özellikle nesne arkasındaki maddelerin görülebilir olması, THz dalgalarının güvenlik sektöründeki kullanımına olan ilgiyi de oldukça artırmıştır. Örneğin; insansız hava araçlarında $\mathrm{THz}$ teknolojisinin kullanılması ile insan olmadan teröristlerin yoğun bir şekilde kullandığı EYP'lerin ve patlayıcı maddelerin tespit edilebilir ve etkisiz hale gelebilir olması bir dönüm noktası olacaktır. Ayrıca; kâğıt, plastik, kumaş, karton, deri vb. materyallerin içerisinde de patlayıcı madde tespit edebilme kabiliyeti kazanmamıza yardımcı olan bu tekniğin savunma sanayinde ülke bekasında ve güvenliğinde efektif bir şekilde kullanılabileceği ve oldukça büyük faydalar sağlayabileceği değerlendirilmektedir. $\mathrm{Bu}$ sebeple, bu teknoloji ülkeler, güvenlik birimleri ve insanlık için önemli bir potansiyele sahiptir.

LIBS, kısa sürede çözüm ve etkili karar vermeyi gerektiren saha ve laboratuvar uygulamaları için umut verici bir yöntemdir. Ancak karmaşık organik yapılarla beraber bulunduğunda ölçümler zorlaşmaktadır. Gelecekte yapılacak çalışmalarla birlikte farklı matematiksel modeller geliştirileceği ve ölçümü zorlaştıran "karıştırıcıların" oluşturduğu zorluklar aşılacaktır. Bu sistemin güvenlik güçlerince kullanılmasının sivil ve askerî kayıpları azaltabileceği düşünülmektedir.

\section{Sonuc}

$\mathrm{Bu}$ çalışmada ele aldığımız sensörler, EM spektrumun geniş bir aralığını taramakta ve aktif veya pasif şekilde çalışmaktadır. Şu anda, spektroskopi tabanlı tespit teknikleri, patlama analizi alanında en gelişmiş olanlardır. $\mathrm{Bu}$ nedenle gelecekte de çok önemli bir rol oynayacağı öngörülmektedir. Fakat hiçbir yöntemin tek başına tüm patlayıcı, mayın ve EYP'leri tespit edemeyeceği de açıktır. 
Günümüzde, lazerler, spektrometreler ve optik yollar paylaş1larak farklı spektral yöntemlerin tek bir cihazda toplanmasına da çalışılmaktadır.

Sensör seçiminden bağımsız olarak çalışılması gereken bir konu da zaman içinde veya çevresel koşullar da değerlendirildiğinde patlayıcıların kimyalarındaki değişmeler ve bozunmalardır. Uzun zaman güneş ışı̆̆ı̆na, yağmura, hava kirliliğine vb. maruz kalan patlayıcıların moleküler yapılarında ve dolayısıyla 1şımalarında ne gibi değişiklikler olabileceği de göz önüne alınmalıdır. Bu yapıların farklı hava sıcaklıklarında, değişik iklim ve coğrafyalarda, nem, 1Sı ve değişik toprak koşullarında farklı moleküler özellikler gösterebileceği veya zamanla değişebileceği de göz önüne alınmalıdır. Dahası, "spektral olarak ayrıştırılabilir" derken aslında spektralarda belli frekanslarda birçok zayıf tepe noktasının çoğu zaman büyük bir gürültü alında gözlendiği anlaşılmalıdır. Dolayısıyla belki donanım kadar belki de ondan daha bile önemli olarak, otomatik tespit yazılımlarının yazılması, büyük ve millî veri tabanlarının hazırlanması ve toplanan verilerin etiketinin bu yazılımlarla konmasına elzem ihtiyaç vardır.

\section{Extended Summary}

Improvised Explosive Devices (IED) are frequently preferred and used in terrorist acts due to their destructive effects, low costs and accessibility. Since they have a wide variety of types and contents and they can be triggered by many mechanisms, IEDs are not easily nor quickly detected. For these reasons, in recent years, efforts to detect IEDs especially in Turkey has become an important issue. In this study, general information about explosives and IEDs and an overview of explosive detection technologies are given. Four spectroscopy-based technologies used in IED detection are discussed with their advantages and disadvantages. These techniques are Hyperspectral Imaging (HSI), Fourier Transform Infrared (FT-IR) Spectroscopy, Terahertz Technology and Laser Induced Breakdown Spectroscopy (LIBS). The technology used in the detection of explosives should be selected according to the type of explosive substance, depth under the ground, chemical components, environmental conditions, sensitivity, speed and the required distance. The active or passive hyperspectral imaging system can be evaluated as a promising technology thanks to its advantages in detecting explosives and chemicals. Hyperspectral imaging technology is actually used in many applications in different industrials. The use of HSI technology will become more common as the system 
El Yapımı Patlayıcıların ve Patlayıcı Maddelerin Tespitinde Kullanılan

Spektroskopi Tabanlı Yöntemlerin Karşılaştırılmasına İlişkin Bir İnceleme

designs become smaller in size, their production increases and their costs decrease. In this way, the hyperspectral imaging method has the potential to enable chemical detection even individually. It is envisaged that HSI can be used with a man or unmanned aerial platform to detect large-scale explosives in the open field and camouflaged targets, which are hard to perceive, and to determine hemp fields of narcotic raw material which is one of the financial sources of terrorism. On account of the FT-IR spectroscopy technique, the spectra of explosive species with different chemical structures can be examined both chemically and functionally. FT-IR spectroscopy technique will likely become an inexpensive and important detection method widely used in the field of security by creating sufficient spectral databases. $\mathrm{THz}$ technology has become the focus of attention in recent years owing to the fact that $\mathrm{THz}$ waves are harmless to human health and their negative effects on the human body are almost negligible compared to X-rays. Thanks to the fact that $\mathrm{THz}$ waves can pass through the materials and penetrate the substances, the objects behind a barrier can be detected. It is believed that this technique, which helps us gain the ability to detect explosives in materials such as paper, plastic, fabric, cardboard, leather, can be used effectively in the defense industry and national security. However, the long times to form these images seem to be the main current hindrance behind this imaging system being used in real-time. LIBS is also a promising method for field and laboratory applications that require solutions and effective decision making in a short time. Due to its point sampling ability, LIBS can even recognize small explosive traces of Nano gram size. It can be used to detect explosive residues on the surfaces of transport vehicles. However, since the laser pulse on the target may cause visible damage, it should never be used on living things. The sensors discussed in this study scan a wide range of the EM spectrum and operate actively or passively. Spectroscopy-based detection techniques are currently one of the most advanced technologies used in the field of explosive detection. However, it is clear that no method alone can detect all explosives, mines and IEDs. Today, many studies are carried out to combine laser, spectrometer and optical spectral methods in a single device. Another issue that needs to be studied independently of the sensor selection is the changes and degradation in explosives chemistry over time or under the influence of environmental conditions. It should also be taken into consideration that there may be changes in the molecular structure and radiation of explosives that are exposed to events such as sunlight, rain and air pollution for a long time. These 
structures may show different molecular properties or change over time at different air temperatures, different climates and geographies, humidity, heat and different soil conditions.

\section{Kaynakça}

\section{Kitaplar}

Gonzalez, R. C. \& Woods, R. E. (2007). Digital Image Processing (3rd Edition). Pearson Prentice Hall.

Griffiths, P.R. ve Haseth, J.A.D. (2007). Fourier Transform Infrared Spectrometry. Wiley.

Jensen, J. R. (2015). Introductory digital image processing: a remote sensing perspective (4th Edition). Pearson Series in Geographic Information Science.

National Research Council. (2004). Existing and Potential Standoff Explosives Detection Techniques. Washington, DC: The National Academies Press.

Naumann, D. (2000). Infrared Spectroscopy in Microbiology. Wiley.

Pellegrino, P.M., Holthoff, E.L., Farrell, M.E., (2015). Laser-Based Optical Detection of Explosives. Florida: CRC Press.

$\mathrm{Pu}, \mathrm{R}$. (2017). Hyperspectral remote sensing: Fundamentals and practices. CRC Press,.

Skoog, D.A., Holler, F.J. ve Nieman, T.A. (1998). Principles of instrumental analysis. Cengage learning.

Venugopalan, S. (2015). Demystifying explosives: concepts in high energy materials. Elsevier.

Yinon, J. (1999). Forensic and Environmental Detection of Explosives. Wiley.

\section{Makaleler}

Adão, T., Hruška, J., Pádua, L., Bessa, J., Peres, E., Morais, R., \& Sousa, J. (2017). Hyperspectral imaging: A review on UAV-based sensors, data processing and applications for agriculture and forestry. Remote Sensing, 9(11), 1110. 
El Yapımı Patlayıcıların ve Patlayıcı Maddelerin Tespitinde Kullanılan

Spektroskopi Tabanlı Yöntemlerin Karşılaştırılmasına İlişkin Bir İnceleme

Anzano, J. M., Gornushkin, I. B., Smith, B. W., \& Winefordner, J. D. (2000). Laserinduced plasma spectroscopy for plastic identification. Polymer Engineering \& Science, 40(11), 2423-2429.

Bioucas-Dias, J. M., Plaza, A., Camps-Valls, G., Scheunders, P., Nasrabadi, N., \& Chanussot, J. (2013). Hyperspectral remote sensing data analysis and future challenges. IEEE Geoscience and remote sensing magazine, 1(2), 6-36.

Blake, T. A., Kelly, J. F., Gallagher, N. B., Gassman, P. L., \& Johnson, T. J. (2009). Passive standoff detection of RDX residues on metal surfaces via infrared hyperspectral imaging. Analytical and bioanalytical chemistry, 395(2), 337348.

Cullum, H. E., McGavigan, C., Uttley, C. Z., Stroud, M. A., \& Warren, D. C. (2004). A second survey of high explosives traces in public places. Journal of Forensic Science, 49(4), 1-7.

Davies, A. G., Burnett, A. D., Fan, W., Linfield, E. H., \& Cunningham, J. E. (2008). Terahertz spectroscopy of explosives and drugs. Materials Today, 11(3), 1826.

Day, J.S., Edwards, H. G. M., Dobrowski, S. A. ve Voice, A. M. (2004). The detection of drugs of abuse in fingerprints using Raman spectroscopy II: cyanoacrylate-fumed fingerprints. Spectrochimica Acta. Part A, Molecular and Biomolecular Spectroscopy, 60(8-9), 1725-1730.

De la Ossa, A.F., Amigo, J.M., Garcia-Ruiz, C., (2014). Detection of residues from explosive manipulation by near infrared hyperspectral imaging: A promising forensic tool. Forensic Science International, 242, 228-235.

Elsherbiny, N., ve Aied Nassef, O. (2015). Wavelength dependence of laser induced breakdown spectroscopy (LIBS) on questioned document investigation. Science \& Justice, 55(4), 254-263.

Ergün, S., ve Sönmez, S. (2015). Terahertz Technology For Military Applications. Journal of Military and Information Science, 3(1), 13.

Habib, M. K. (2007). Controlled biological and biomimetic systems for landmine detection. Biosensors and Bioelectronics, 23(1), 1-18 
Gottfried, J. L., De Lucia, F. C., Munson, C. A., \& Miziolek, A. W. (2009). Laserinduced breakdown spectroscopy for detection of explosives residues: a review of recent advances, challenges, and future prospects. Analytical and Bioanalytical Chemistry, 395(2), 283-300.

Grant, A., Wilkinson, T.J., Holman, D.R. \& Martin, M.C. (2005). Identification of recently handled materials by analysis of latent human fingerprints using infrared spectromicroscopy. Applied Spectroscopy, 59(9), 1182-1187.

Hybl, J.D., Lithgow, G.A., Buckley S.G. (2003). Laser-induced breakdown spectroscopy detection and classification of biological aerosols. Applied Spectroscopy, 57, pp.1207.

Iqbal, Z., Suryanarayanan, K., Bulusu, S., \& Autera, J. R. (1972). Infrared and Raman Spectra of 1, 3, 5-trinitro-1, 3, 5-triazacyclohexane (RDX) (No. PATR-4401). PICATINNY ARSENAL DOVER NJ.

Junjuri R., Myakalwar A.K., Gundawar M.K. (2017) Standoff Detection of Explosives at $1 \mathrm{~m}$ using Laser Induced Breakdown Spectroscopy, Defence Science Journal, 67 (6), pp. 623-630.

Kemp, M. C. (2011) Explosives Detection by Terahertz Spectroscopy-A Bridge Too Far? IEEE Transactions on Terahertz Science and Technology, 1 (1), pp. 282-292.

Kı1ıç, G. B., \& Karahan, A. G. (2010). Fourier Dönüşümlü Kızılötesi (FTIR) Spektroskopisi ve Laktik Asit Bakterilerinin Tanısında Kullanılması. GIDA, 35(6), 445-452.

Koz, A. (2019). Ground-Based Hyperspectral Image Surveillance Systems for Explosive Detection: Part I-State of the Art and Challenges. IEEE Journal of Selected Topics in Applied Earth Observations and Remote Sensing, 12 (12), 4746-4753.

Kumar, M., Islam, M. N., Terry, F. L., Freeman, M. J., Chan, A., Neelakandan, M., \& Manzur, T. (2012). Stand-off detection of solid targets with diffuse reflection spectroscopy using a high-power mid-infrared supercontinuum source. Applied Optics, 51(15), 2794-2807. 
El Yapımı Patlayıcıların ve Patlayıcı Maddelerin Tespitinde Kullanılan Spektroskopi Tabanlı Yöntemlerin Karşılaştırılmasına İlişkin Bir İnceleme

Kunz, R. R., Gregory, K. E., Aernecke, M. J., Clark, M. L., Ostrinskaya, A., \& Fountain III, A. W. (2012). Fate dynamics of environmentally exposed explosive traces. The Journal Of Physical Chemistry A, 116(14), 3611-3624.

Leahy-Hoppa, M.R., Fitch, M.J., Osiander, R. (2009). Terahertz spectroscopy techniques for explosives detection. Analytical and Bioanalytical Chemistry, 395 (2), pp 247-257.

McCanta, M. C., Dobosh, P. A., Dyar, M. D., \& Newsom, H. E. (2013). Testing the veracity of LIBS analyses on Mars using the LIBSSIM program. Planetary and Space Science, 81, 48-54.

Moros J., Lorenzo J.A., Lucena P., Tobaria L.M., Laserna J.J. (2010) Simultaneous Raman spectroscopy-laser-induced breakdown spectroscopy for instant standoff analysis of explosives using a mobile integrated sensor platform. Anal. Chem. 82, 1389.

Munson, C. A., Gottfried, J. L., De Lucia Jr, F. C., McNesby, K. L., \& Miziolek, A. W. (2007). Laser-based detection methods of explosives. In Counterterrorist Detection Techniques of Explosives (pp. 279-321). Elsevier Science BV.

Oxley, J. C., Smith, J. L., Kirschenbaum, L. J., \& Marimganti, S. (2007). Accumulation of explosives in hair-part II: factors affecting sorption. Journal of Forensic Sciences, 52(6), 1291-1296.

Oxley, J. C., Smith, J. L., Kirschenbaum, L. J., Marimganti, S., Efremenko, I., Zach, R., and Zeiri, Y. (2012) Accumulation of explosives in hair-Part 3: Binding site study. Journal of Forensic Sciences, 57(3), 623-635.

Politzer, P., \& Murray, J. S. (2014). Detonation performance and sensitivity: a quest for balance. In Advances in quantum chemistry, 69, pp. 1-30. Academic Press.

Portnov, A., Rosenwaks, S., Bar I. (2003) Emission following laser-induced breakdown spectroscopy of organic compounds in ambient air. Applied Optics, 42, pp. 2835.

Plaza, A., Benediktsson, J. A., Boardman, J. W., Brazile, J., Bruzzone, L., CampsValls, G., Chanussot, J., Fauvel, M., Gamba P., Gualtieri, A., \& Marconcini, 
M. (2009). Recent advances in techniques for hyperspectral image processing. Remote sensing of environment, 113, S110-S122.

Shankaran, D. R., Gobi, K. V., Sakai, T., Matsumoto, K., Imato, T., Toko, K., \& Miura, N. (2005). A novel surface plasmon resonance immunosensor for 2, 4, 6-trinitrotoluene (TNT) based on indirect competitive immunoreaction: a promising approach for on-site landmine detection. IEEE Sensors Journal, 5(4), 616-621.

Stine, J. R. (1992). Molecular structure and performance of high explosives. MRS Online Proceedings Library Archive, 296.

Ueno, Y., \& Ajito, K. (2008). Analytical terahertz spectroscopy. Analytical Sciences, 24(2), 185-192.

Wang, Q., Teng, G., Li, C., Zhao, Y., \& Peng, Z. (2019). Identification and classification of explosives using semi-supervised learning and laserinduced breakdown spectroscopy. Journal of Hazardous Materials, 369, $423-429$.

Wang, Y., P. Reder, N., Kang, S., Glaser, A., Liu, J., (2017). Multiplexed Optical Imaging of Tumor-Directed Nanoparticles: A Review of Imaging Systems and Approaches. Nanotheranostics. 1(4), 369-388.

Yüksel, S. E., \& Boyac1, M. (2018). Effect of LiDAR sensor on the success of shadow detection from hyperspectral data. Pamukkale University Journal of Engineering Sciences - Pamukkale Üniversitesi Mühendislik Bilimleri Dergisi, 24(2), 198-204.

Yüksel, S.E., Karakaya, A. (2016a) Fusion of Target Detection Algorithms in Hyperspectral Images. International Journal of Intelligent Systems and Applications in Engineering, 4(4), 103-110, 2016.

Yüksel, S.E., Kucuk, S., Gader, P., (2016b) SPICEE: An Extension of SPICE for Sparse Endmember Estimation in Hyperspectral Imagery. IEEE Geoscience and Remote Sensing Letters, 13(12), 1910-1914. 
El Yapımı Patlayıcıların ve Patlayıcı Maddelerin Tespitinde Kullanılan

Spektroskopi Tabanlı Yöntemlerin Karşılaştırılmasına İlişkin Bir İnceleme

Yüksel, S.E., Dubroca, T., Hummel, R.E., Gader, P.D. (2013) Differential Reflection Spectroscopy: A Novel Method for Explosive Detection. Acta Physica Polonica A, 123 (2), pp. 263- 264.

Zhang W, Tang Y., Shi A., Bao L., Shen Y., Shen R., and Ye Y. (2018) Recent Developments in Spectroscopic Techniques for the Detection of Explosives. Materials. 11(8), 1364.

\section{Sempozyum, Kongre ve Konferans Bildirileri}

Aydın, E., \& Erdem, S.E.Y. (2019, May). Transfer and multitask learning using convolutional neural networks for buried wire detection from ground penetrating radar data. In Detection and Sensing of Mines, Explosive Objects, and Obscured Targets XXIV (Vol. 11012, p. 110120Y). International Society for Optics and Photonics.

Bernacki, B. E., \& Phillips, M. C. (2010, May). Standoff hyperspectral imaging of explosives residues using broadly tunable external cavity quantum cascade laser illumination. In Chemical, Biological, Radiological, Nuclear, and Explosives (CBRNE) Sensing XI (Vol. 7665, p. 76650I). International Society for Optics and Photonics.

Bingham, A. L., Lucey, P. G., Akagi, J. T., Hinrichs, J. L., \& Knobbe, E. T. (2014, May). LWIR hyperspectral micro-imager for detection of trace explosive particles. In Next-Generation Spectroscopic Technologies Vii (Vol. 9101, p. 91010Z). International Society for Optics and Photonics.

Chirico, R., Almaviva, S., Botti, S., Cantarini, L., Colao, F., Fiorani, L., Nuvoli, M., \& Palucci, A. (2012, October). Stand-off detection of traces of explosives and precursors on fabrics by UV Raman spectroscopy. In Optics and Photonics for Counterterrorism, Crime Fighting, and Defence VIII (Vol. 8546, p. 85460W). International Society for Optics and Photonics.

Fuchs, F., Wild, C., Kirn, B., Bronner, W., Raynor, B., Köhler, K., \& Wagner, J. (2007, November). Remote sensing of explosives using mid-infrared quantum cascade lasers. In Electro-Optical Remote Sensing, Detection, and Photonic Technologies and Their Applications (Vol. 6739, p. 673904). International Society for Optics and Photonics. 
Fuchs, F., Jarvis, J. P., Hugger, S., Kinzer, M., Yang, Q., Bronner, W., Driad R., \& Aidam, R. (2012, September). Imaging standoff detection of explosives by diffuse reflectance IR laser spectroscopy. In Future Security Research Conference (pp. 388-399). Springer, Berlin, Heidelberg.

Hildenbrand, J., Herbst, J., Wöllenstein, J., \& Lambrecht, A. (2009, January). Explosive detection using infrared laser spectroscopy. In Quantum sensing and nanophotonic devices VI (Vol. 7222, p. 72220B). International Society for Optics and Photonics.

Nelson, M. P., Basta, A., Patil, R., Klueva, O., \& Treado, P. J. (2013, May). Development of a handheld widefield hyperspectral imaging (HSI) sensor for standoff detection of explosive, chemical, and narcotic residues. In NextGeneration Spectroscopic Technologies VI (Vol. 8726, p. 872605). International Society for Optics and Photonics.

Onat, B. M., Carver, G., \& Itzler, M. (2009, April). A solid-state hyperspectral imager for real-time standoff explosives detection using shortwave infrared imaging. In Non-Intrusive Inspection Technologies II (Vol. 7310, p. 731004). International Society for Optics and Photonics.

Ruxton, K., Robertson, G., Miller, W., Malcolm, G. P. A., \& Maker, G. T. (2012, October). Mid-infrared hyperspectral imaging for the detection of explosive compounds. In Optics and Photonics for Counterterrorism, Crime Fighting, and Defence VIII (Vol. 8546, p. 85460V). International Society for Optics and Photonics.

Sakarya, U., Teke, M., Demirkesen, C., Haliloğlu, O., Kozal, A. Ö., Deveci, H. S., \& Gürbüz, S. Z. (2015, June). A short survey of hyperspectral remote sensing and hyperspectral remote sensing research at TÜBİTAK Uzay. In 2015 7th International Conference on Recent Advances in Space Technologies (RAST) (pp. 187-192). IEEE.

Waterbury, R., Rose, J., Vunck, D., Blank, T., Pohl, K., Ford, A. \& Dottery, E. (2011, June). Fabrication and testing of a standoff trace explosives detection system. In Chemical, Biological, Radiological, Nuclear, and Explosives (CBRNE) Sensing XII (Vol. 8018, p. 801818). International Society for Optics and Photonics. 
El Yapımı Patlayıcıların ve Patlayıcı Maddelerin Tespitinde Kullanılan

Spektroskopi Tabanlı Yöntemlerin Karşılaştırılmasına İlişkin Bir İnceleme

Yüksel, S. E., Akar, G. B., \& Öztürk, S. (2015, May). Fusion of forward-looking infrared camera and down-looking ground penetrating radar for buried target detection. In Detection and Sensing of Mines, Explosive Objects, and Obscured Targets XX (Vol. 9454, p. 945418). International Society for Optics and Photonics.

Yüksel, S. E., Dubroca, T., Hummel, R. E., \& Gader, P. D. (2012, May). An automatic detection software for differential reflection spectroscopy. In Algorithms and Technologies for Multispectral, Hyperspectral, and Ultraspectral Imagery XVIII (Vol. 8390, p. 83900B). International Society for Optics and Photonics.

Zhong, H., Karpowicz, N., Partridge, J., Xie, X., Xu, J., \& Zhang, X. C. (2004, September). Terahertz wave imaging for landmine detection. In Terahertz for Military and Security Applications II (Vol. 5411, pp. 33-44). International Society for Optics and Photonics.

\section{Tezler}

Küçük, S. (2015). Uzun Dalga Kızılötesi Hiperspektral Görüntülerde Hedef Tespiti. Yüksek Lisans Tezi, Hacettepe Üniversitesi, Ankara.

Makki, I., (2017). Hyperspectral Imaging for Landmine Detection. Ph.D. Thesis. Optimization and Control. Politecnico Di Torino.

Tekbaş, M. (2014). Terahertz görüntüleme ve tanıma sistemleri. Yüksek Lisans Tezi, Bilecik Şeyh Edebali Üniversitesi, Bilecik.

\section{Elektronik Kaynaklar}

Beşergil, B. FTIR Absorbsiyon Spektroskopisi. 25 Mayıs 2019'da http://bilsenbesergil.blogspot.com/p/8_44.html adresinden alınmıştır.

Bingöl, O. ve Varlık, A.B., (2015). EYP Semineri - 1 Sonuç Raporu (merkezstrateji. com /assets/media/01-eyp-semineri-sonuc-raporu-tesud-mse-s1_1.pdf).

Cross, R. (2017) Glowing bacteria detect buried landmines. 19 Temmuz 2020'de https://www.sciencemag.org/news/2017/04/glowing-bacteria-detect-buriedlandmines adresinden alınmıştır.

Emission Line. (2019). 19 Temmuz 2020'de https://astronomy.swin.edu.au/cosmos 
/E/emission+line adresinden alınmıştır.

Faust, B. (1997). Modern Chemical Techniques: An Essential Reference for Students and Teachers. http:// www. rsc.org/l earnchemistry/ resource/ res00001299/ infrared-spectroscopy adresinden alınmıştır.

Five ways to better protect civilians in conflict zones. (2019). 2 Mayıs 2019'da www.unocha.org adresinden alınmıştır.

Guest, T. (2020) Detecting Explosives Science, Technological Innovation and Solutions. 19 Temmuz 2020'de https://euro-sd.com/2020/03/allgemein/ 16541/detecting-explosives-science-technological-innovation-and-solutions adresinden alınmıştır.

Korvink, J. G., Badilita, V. \& Abdo, M. (2018) Hyperspectral Imaging. 19 Temmuz 2020'de https://www.imt.kit.edu/hyper-spectral-imaging.phpadresinden alınmıştır.

Paula, B. (2016) Organic_Chemistry. 25 May1s 2019'da https://chem.libretexts.org /Bookshelves/Organic_Chemistry/Map\%3A_Organic_Chemistry_(Bruice)/ 13\%3A_Mass_Spectrometry\%2C_Infrared_Spectroscopy\%2C_and_Ultrav iolet $\% 2 \mathrm{~F} \% 2 \mathrm{FVisible}$ SSpectroscopy adresinden alınmıştır. 
El Yapımı Patlayıcıların ve Patlayıcı Maddelerin Tespitinde Kullanılan

Spektroskopi Tabanlı Yöntemlerin Karşılaştırılmasına İlişkin Bir İnceleme

EK

\section{PATLAYICILAR}

\begin{tabular}{|c|c|}
\hline Adı/Kısaltması & Kimyasal Formülü \\
\hline AN (ammonium nitrate) & $\mathrm{NH}_{4} \mathrm{NO}_{3}$ \\
\hline Amonyum Perklorat & $\mathrm{NH}_{4} \mathrm{ClO}_{4}$ \\
\hline Amonyum Pikrat & $\mathrm{C}_{6} \mathrm{H}_{4} \mathrm{~N}_{4} \mathrm{O}_{7}$ \\
\hline DADP (diacetone diperoxide) & $\mathrm{C}_{6} \mathrm{H}_{12} \mathrm{O}_{4}$ \\
\hline DDNP (diazodinitrophenol) & $\mathrm{C}_{6} \mathrm{H}_{2} \mathrm{~N}_{4} \mathrm{O}_{5}$ \\
\hline Dinamit & $\mathrm{CH}_{2} \mathrm{NO}_{3} \mathrm{CHNO}_{3} \mathrm{CH}_{2} \mathrm{NO}_{3}+$ Diatomit \\
\hline HMX (high melting explosive) & $\mathrm{C}_{4} \mathrm{H}_{8} \mathrm{~N}_{8} \mathrm{O}_{8}$ \\
\hline Kurşun Azit & $\mathrm{PbN}_{6}$ \\
\hline Kurşun Pikrat & $\mathrm{Pb}\left(\mathrm{C}_{6} \mathrm{H}_{2}\left(\mathrm{NO}_{2}\right)_{3} \mathrm{O}\right)_{2}$ \\
\hline Nitroselüloz & {$\left[\mathrm{C}_{6} \mathrm{H}_{9}\left(\mathrm{NO}_{2}\right) \mathrm{O}_{5}\right]_{\mathrm{n}}$} \\
\hline Nitroglicerin & $\mathrm{C}_{3} \mathrm{H}_{5} \mathrm{~N}_{3} \mathrm{O}_{9}$ \\
\hline PETN (pentaeritritol tetranitrate) & $\mathrm{C}_{5} \mathrm{H}_{8} \mathrm{~N}_{4} \mathrm{O}_{12}$ \\
\hline Pikrik Asit & $\mathrm{C}_{6} \mathrm{H}_{3} \mathrm{~N}_{3} \mathrm{O}_{7}$ \\
\hline RDX (royal demolition explosive) & $\mathrm{C}_{3} \mathrm{H}_{6} \mathrm{~N}_{6} \mathrm{O}_{6}$ \\
\hline TNT (trinitrotoluen) & $\mathrm{C}_{7} \mathrm{H}_{5} \mathrm{~N}_{3} \mathrm{O}_{6}$ \\
\hline TETRYL (trinitrophenylmethylnitramine) & $\mathrm{C}_{7} \mathrm{H}_{5} \mathrm{~N}_{5} \mathrm{O}_{8}$ \\
\hline TATP (triacetone triperoxide) & $\mathrm{C}_{9} \mathrm{H}_{18} \mathrm{O}_{6}$ \\
\hline
\end{tabular}

